Research Division

Federal Reserve Bank of St. Louis

Working Paper Series

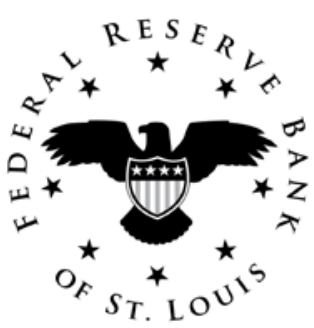

\title{
What Inventories Tell Us about Aggregate Fluctuations A Tractable Approach to (S,s) Policies
}

\author{
Pengfei Wang \\ Yi Wen \\ and \\ Zhiwei Xu
}

Working Paper 2012-059B

http://research.stlouisfed.org/wp/2012/2012-059.pdf

November 2012

Revised March 2014

FEDERAL RESERVE BANK OF ST. LOUIS

Research Division

P.O. Box 442

St. Louis, MO 63166

The views expressed are those of the individual authors and do not necessarily reflect official positions of the Federal Reserve Bank of St. Louis, the Federal Reserve System, or the Board of Governors.

Federal Reserve Bank of St. Louis Working Papers are preliminary materials circulated to stimulate discussion and critical comment. References in publications to Federal Reserve Bank of St. Louis Working Papers (other than an acknowledgment that the writer has had access to unpublished material) should be cleared with the author or authors. 


\title{
What Inventories Tell Us about Aggregate Fluctuations

\author{
- A Tractable Approach to (S,s) Policies*
}

\author{
Pengfei Wang $^{a} \quad$ Yi Wen ${ }^{b} \quad$ Zhiwei $\mathrm{Xu}^{c}$
}

This version: March 2014

\begin{abstract}
We estimate a DSGE model with $(\mathrm{S}, \mathrm{s})$ inventory policies. We find that (i) taking inventories into account can significantly improve the empirical fit of DSGE models in matching the standard business-cycle moments (in addition to explaining inventory fluctuations); (ii) (S,s) inventory policies can significantly amplify aggregate output fluctuations, in contrast to the findings of the recent general-equilibrium inventory literature; and (iii) aggregate demand shocks become more important than technology shocks in explaining the business cycle once inventories are incorporated into the model. An independent contribution of our paper is that we develop a solution method for analytically solving $(\mathrm{S}, \mathrm{s})$ inventory policies in general-equilibrium models with heterogeneous firms and a large aggregate state space, and we illustrate how standard log-linearization methods can be used to solve various versions of our inventory model, generate impulse response functions, and estimate the model's deep structural parameters.
\end{abstract}

Keywords: (S,s) Inventories Policy, State-Dependent Decisions, HeterogeneousAgent Models, Perturbation Methods.

JEL codes: E13, E22, E32.

\footnotetext{
${ }^{*} a$ : Hong Kong University of Science and Technology; $b$ : Federal Reserve Bank of St. Louis and Tsinghua University; c: Antai College of Economics and Management, Shanghai Jiao Tong University. Corresponding author: Pengfei Wang, Department of Economics, Hong Kong University of Science and Technology, Hong Kong, China. Phone: 852-2358-7612. Email: pfwang@ust.hk. We thank the editor, two anonymous referees, and seminar participants at various institutions for very valuable comments. Pengfei Wang acknowledges the financial support from Hong Kong Research Grants OCGA (project \#RPC11BM05). The usual disclaimer applies.
} 


\section{Introduction}

Inventories and inventory investment are a large part of economic activities. For example, for the post-war period, the stock of finished goods inventories is about $60 \%$ of quarterly gross domestic product (GDP) and $83 \%$ of aggregate consumption. In addition, despite the tiny share of inventory investment in GDP (less than 1\% on average), the drop in inventory investment often accounts for the bulk of the drop in GDP in post-war recessions. ${ }^{1}$ It is in this sense Blinder (1981) concludes that "to a great extent, business cycles are inventory fluctuations" (Blinder, 1981, p.500).

The question why inventories are so volatile and apparently contribute so much to aggregate output fluctuations still remains a puzzle despite more than three decades of intensive research since Blinder's work. Conventional wisdom has it that inventory investment contributes greatly to the business cycle because it comoves with sales (see, e.g., Blinder 1981; Blinder and Maccini, 1991). However, Khan and Thomas (2007a) and Wen (2011) show that this conventional wisdom may be wrong from a general-equilibrium viewpoint. Using general-equilibrium frameworks with microfoundations for firms' inventory demand behaviors, these authors show that inventories do not amplify the business cycle even though changes in the inventory stock are procyclical and can be 10-20 times more volatile than GDP.

Despite the importance of inventories in economic activity and their potential role in understanding the business cycle, full-fledged general-equilibrium analysis of inventories with explicit microfoundations is still rare. In addition, even if microfoundations of inventory behaviors are provided in general-equilibrium models, as in the recent analyses of Fisher and Hornstein (2000), Khan and Thomas (2007a), Wang and Wen (2009), and Wen (2011), this literature so far has relied on calibrations and a single aggregate shock (or one shock at a time) to study the implications of inventory fluctuations for the business cycle. Thus, quantitative questions such as how much can inventories explain the business cycle and how important are different sources of aggregate shocks in generating the inventory cycle and output fluctuations remained largely unanswered by this recent microfounded general-

\footnotetext{
${ }^{1}$ See Wen (2005). As a more recent example, in the 1982 recession period, real GDP (in year 2000 price) dropped 252 billion dollars below trend and the total inventory stock dropped 219 billion dollars below trend, nearly $87 \%$ of the drop in GDP. Even during the recent financial crisis, the fall in inventory investment accounts for $29 \%$ of the decline in GDP.
} 
equilibrium inventory literature.

Part of the reason for this lack of formal econometric estimation and variance decomposition in a microfounded general-equilibrium inventory model is computation costs, especially when inventories are introduced through the $(\mathrm{S}, \mathrm{s})$ policy rule. ${ }^{2}$ Even though $(\mathrm{S}, \mathrm{s})$ inventory models based on fixed order costs are an important framework for studying inventory dynamics and their interactions with the business cycle, ${ }^{3}$ a fundamental challenge for working with this framework, however, is computability and tractability. Blinder once commented:

If firms have a technology that makes the $\mathrm{S}, \mathrm{s}$ rule optimal, aggregation across firms is inherently difficult. Indeed it is precisely this difficulty which has prevented the $\mathrm{S}$, s model from being used in empirical work to date (Blinder [1981, p. 459]).

We build a microfounded, fully-fledged dynamic stochastic general equilibrium (DSGE) $(\mathrm{S}, \mathrm{s})$ inventory model with both idiosyncratic and aggregate shocks as well as real rigidities. Firms hold inventories to minimize fixed order costs for intermediate inputs. Under idiosyncratic firm-specific fixed cost shocks, there exists a well defined distribution of inventoryholding firms characterized by $(\mathrm{S}, \mathrm{s})$ policy rules. We estimate the key structural parameters of the model by the method of simulated moments and we obtain the following new findings:

1. Taking inventories into account can significantly improve the empirical fit of a DSGE model in matching standard business-cycle moments, in addition to explaining inventory fluctuations.

2. Consistent with the conventional wisdom, we find that inventories amplify the business cycle significantly in our microfounded general-equilibrium inventory model, in contrast to the findings of the existing general-equilibrium inventory literature (i.e., Khan and Thomas, 2007a; and Wen, 2011).

3. Incorporating inventories into our model enhances the role of transitory (especially aggregate demand) shocks as a driving force of the business cycle and makes demand shocks more important than technology shocks in explaining short-run fluctuations in aggregate output.

\footnotetext{
${ }^{2}$ See Wen (2011) for a tractable, microfounded inventory model based not on the (S,s) rule but on the stockout-avoidance motive.

${ }^{3}$ Important works include Blinder (1981); Caplin (1985); Caballero and Engel (1991); Fisher and Hornstein (2000); and Khan and Thomas (2007a), among others.
} 
Our findings suggest that inventories arising from minimizing fixed order costs are important for understanding the general features of the business cycle. Models that ignore inventories may lead to incomplete understanding of economic fluctuations or biased estimations about the relative importance of different shocks.

An independent contribution of this paper is computational. The presence of fixed order costs in an $(\mathrm{S}, \mathrm{s})$ inventory model yields a discrete ordering decision, which makes a firm's dynamic programming problem nonconvex. In addition, the occasionally binding nonnegative nature of inventory holdings imposes a nonlinear constraint on a firm's inventory stock, which makes a firm's value function not differentiable everywhere. General equilibrium analysis compounds the difficulties because in general equilibrium, one needs to track the distribution of inventory holdings at the firm level for any given macro state space (such as the aggregate capital stocks, the level of wealth or asset holdings, lagged aggregate investment and consumption, inventory distributions, and aggregate shocks), yet part of the macro state space is itself determined by the sum of individual firms' inventory decisions. Due to the curse of dimensionality, numerical computation methods such as the one proposed by Krusell and Smith (1998) become increasingly difficult to implement if the state space is relatively large, as is the case in our model or many standard macro models (that feature multiple capital stocks, investment adjustment costs, habit formation, or multiple aggregate shocks). Estimating such a model requires solving the model repeatedly, making it a close-to-impossible task under the Krusell-Smith numerical method. In addition, the Krusell-Smith method cannot guarantee the existence and uniqueness of equilibrium, as discussed by Miao and Wang (2013) and others.

This paper overcomes this technical hurdle by making $(\mathrm{S}, \mathrm{s})$ inventory policies in general equilibrium models tractable despite a potentially very large aggregate state space. Our approach builds on the strategy of Dotsey et al. (1999) in the state-dependent pricing literature. ${ }^{4}$ Due to the i.i.d. nature of fixed order costs, we show that all ordering firms have the same inventory target regardless of their inventory level in the previous period. And given a firm's inventory level in the previous period, the ordering decision follows a trigger (cutoff) strategy. Firms will order if and only if the fixed cost is below a unique threshold.

\footnotetext{
${ }^{4}$ However, in an $(\mathrm{S}, \mathrm{s})$ inventory model, the problem at the firm level is more complex than that in the Dotsey-King-Wolman model. In our model, an inactive firm also needs to solve a dynamic optimization problem to determine the optimal inventory level, whereas in the state-dependent pricing model inactive firms simply set the current price to the previous level, and in the lumpy-investment model inactive firms simply set the current investment to zero. For the literature on state-dependent $(\mathrm{S}, \mathrm{s})$ inventory policies, see Caplin (1985), Caplin and Leahy (1991), Caballero and Engel (1991), Fisher and Hornstein (2000), and Thomas (2002).
} 
Such a structure implies that firms are distinguished only by the time since their last order was made, so the distribution of inventories in the economy is discrete with finite support points and the optimal cutoff for each vintage-firm group is history-independent. That is, regardless of the history of idiosyncratic shocks, firms that have placed orders in period $t-j$ will have the same amount of inventories if they have not ordered in the last $j$ periods. In addition, firms that opt to order in the current period will replenish their inventory to the same level regardless of their existing inventory level. So we can group firms according to the time when their last order was made. This leads to a block-recursive structure in the model, which permits exact aggregation and closed-form characterization of the general equilibrium.

Hence, the aggregate variables in the model form a system of nonlinear rational expectations equations that look identical to those in a standard representative-agent model. Standard solution methods available in the RBC literature (such as log-linearization around the steady state and higher-order perturbation methods) can then be applied straightforwardly to solve the model's aggregate equilibrium paths, generate impulse response functions under aggregate shocks, and estimate the model's structural parameters by standard econometrics.

The rest of the paper is organized as follows. Section 2 presents a baseline generalequilibrium inventory model with idiosyncratic fixed order costs, multiple aggregate shocks, and several predetermined aggregate control variables. Section 3 derives the firm's (S,s) inventory rules in closed form. Section 4 studies the steady-state distributions of inventories and compares the results with those of the existing literature (e.g., Khan and Thomas, 2007a). Sections 5 and 6 estimate the structural parameters of the model and study the model's business-cycle dynamics. Section 7 concludes the paper.

\section{The Baseline Inventory Model}

Our model builds on the literature of (S,s) inventory policies (e.g., Blinder, 1981; Caplin, 1985; Caballero and Engel, 1991; Fisher and Hornstein, 2000; and Khan and Thomas, 2007a; among others). However, since Khan and Thomas (2007a) show that (S,s) inventory behaviors do not matter for understanding output fluctuations in general equilibrium, it is natural for us to adopt the Khan-Thomas (KT) framework as a benchmark for our analysis; but we enrich the KT model by introducing multiple aggregate shocks and several real frictions to improve the model's empirical fit. More specifically, we allow for two types of technology shocks - a shock to technology growth and a shock to its level. This setup ensures that we do not underestimate the importance of technology shocks in our inventory model (since it gives 
supply-side shocks a better chance to explain the business cycle in our estimation procedure). We also allow a single source of aggregate demand shocks (represented by preference shocks in this paper), habit formation, investment adjustment costs, and variable capacity utilization. Notice that these additional features will render numerical solution techniques, such as the one proposed by Krusell and Smith (1998) and adopted by KT, difficult to implement because the state space is further enlarged by multiple aggregate shocks and predetermined variables (such as lagged consumption and lagged investment). However, these features do not impose additional difficulties on our tractable solution method. We will show that our enriched model performs much better than the KT model in explaining the business cycle and inventory fluctuations. More importantly, we will show that within this framework, inventories do matter for understanding the business cycle.

The economy has three types of agents: households, intermediate goods producers, and final goods firms. Households derive utility from consumption and leisure according to a quasi-linear utility function with indivisible labor. Households supply labor to all the firms and purchase consumption goods from the final goods firms. Intermediate goods firms produce output using capital and labor. They also accumulate capital by making fixed investment, which is subject to investment adjustment costs. Intermediate goods producers can also vary the capital utilization rate to adjust production level. The final goods firms must pay fixed (stochastic) costs to order intermediate goods and they combine intermediate goods with labor to produce final goods. The final goods can be used either as consumption goods or investment goods. Given the fixed costs of placing orders, final goods firms have incentives to carry inventories to reduce the average order costs.

\subsection{Households}

As in KT, all households are identical (with a unit mass) and labor supply is indivisible. Households supply labor to both the final goods sector and the intermediate goods sector. Due to perfect labor mobility, the real wages are equalized across the two sectors. The final good is used as the numeraire.

A representative household chooses consumption $\left(C_{t}\right)$ and labor supply $\left(N_{t}\right)$ to solve

$$
\max E_{0} \sum_{t=0}^{\infty} \beta^{t}\left[\Delta_{t} \log \left(C_{t}-\chi C_{t-1}\right)+\tau\left(1-N_{t}\right)\right]
$$

subject to the budget constraint

$$
C_{t} \leq W_{t} N_{t}+\Pi_{t}
$$


where $W_{t}$ is the wage rate, $\Pi_{t}$ is the aggregate profits from all the firms, $\chi \in[0,1)$ is the habit-formation parameter, and $\Delta_{t}$ is a preference shock that follows an $\operatorname{AR}(1)$ process in logarithm:

$$
\log \Delta_{t}=\rho_{\Delta} \log \Delta_{t-1}+\varepsilon_{\Delta t}, \quad \varepsilon_{\Delta t} \sim i i d\left(0, \sigma_{\Delta}^{2}\right)
$$

Households behave competitively, and their first-order conditions with respect to consumption and leisure are

$$
\begin{gathered}
\Lambda_{t}=\frac{\Delta_{t}}{C_{t}-\chi C_{t-1}}-\beta \chi E_{t} \frac{\Delta_{t+1}}{C_{t+1}-\chi C_{t}} \\
\tau=\Lambda_{t} W_{t},
\end{gathered}
$$

where the marginal utility $\Lambda_{t}$ is also the shadow price of consumption goods. So $\beta \Lambda_{t+1} / \Lambda_{t}$ will be the pricing kernel for a firm's market value.

\subsection{Intermediate Goods Firms}

A large number of identical intermediate goods firms combine capital $K_{t}$ and labor $L_{t}$ to produce intermediate goods and make investment to accumulate capital. A representative intermediate goods firm maximizes the discounted future dividends:

$$
E_{0} \sum_{t=0}^{\infty} \beta^{t} \frac{\Lambda_{t}}{\Lambda_{0}}\left(P_{t} X_{t}-W_{t} L_{t}-I_{t}\right)
$$

where $P_{t}$ is the price of intermediate goods, $X_{t}$ is the output, and $I_{t}$ is the total investment expenditure. Given its predetermined capital stock $K_{t}$, the intermediate goods firm can vary its capital utilization rate $e_{t}$ and labor input $L_{t}$ to produce output according to the technology:

$$
X_{t}=A_{t}\left(e_{t} K_{t}\right)^{\alpha} L_{t}^{1-\alpha}
$$

where the aggregate technology shock $A_{t}$ has two components, $A_{t}=A_{t}^{P} A_{t}^{T}$, where $A_{t}^{P}$ is the permanent component that evolves according to the law of motion,

$$
A_{t}^{P}=A_{t-1}^{P} g_{t}, \quad \log \left(g_{t}-\bar{g}\right)=\rho_{g} \log \left(g_{t-1}-\bar{g}\right)+\varepsilon_{g t}, \quad \varepsilon_{g t} \sim i i d\left(0, \sigma_{g}^{2}\right)
$$

$g_{t}$ is the growth rate with steady-state value $\bar{g} \geq 1$, and $A_{t}^{T}$ is the transitory component that evolves according to

$$
\log A_{t}^{T}=\rho_{T} \log A_{t-1}^{T}+\varepsilon_{T t}, \quad \varepsilon_{T t} \sim i i d\left(0, \sigma_{T}^{2}\right)
$$


We assume that the depreciation rate of capital is strictly increasing and convex in $e_{t}$ :

$$
\delta_{t}=\delta_{0}+\delta_{1} e_{t}^{\gamma}, \quad \gamma>1
$$

Investment is subject to investment adjustment costs, so the law of capital accumulation is given by

$$
K_{t+1}=\left[1-\delta\left(e_{t}\right)\right] K_{t}+\left[1-\varphi\left(\frac{I_{t}}{I_{t-1}}\right)\right] I_{t}
$$

The adjustment cost function $\varphi(\cdot)$ is strictly increasing and convex with the property that $\varphi(1)=\varphi^{\prime}(1)=0$ and $\varphi^{\prime \prime}(1)>0$.

Denoting $\eta_{t}$ as the Lagrangian multiplier for equation (11), the first-order conditions for $\left\{K_{t+1}, e_{t}, I_{t}, L_{t}\right\}$ are given, respectively, by

$$
\begin{gathered}
\beta E_{t}\left[\frac{\Lambda_{t+1}}{\Lambda_{t}}\left(\alpha P_{t+1} \frac{X_{t+1}}{K_{t+1}}+\left[1-\delta\left(e_{t+1}\right)\right] \eta_{t+1}\right)\right]=\eta_{t}, \\
\alpha P_{t} \frac{X_{t}}{e_{t} K_{t}}=\eta_{t} \delta^{\prime}\left(e_{t}\right), \\
1=\beta E_{t}\left[\frac{\Lambda_{t+1}}{\Lambda_{t}} \eta_{t+1} \varphi^{\prime}\left(\frac{I_{t+1}}{I_{t}}\right)\left(\frac{I_{t+1}}{I_{t}}\right)^{2}\right]+\eta_{t}\left[1-\varphi\left(\frac{I_{t}}{I_{t-1}}\right)-\varphi^{\prime}\left(\frac{I_{t}}{I_{t-1}}\right) \frac{I_{t}}{I_{t-1}}\right], \\
(1-\alpha) P_{t} \frac{X_{t}}{L_{t}}=W_{t} .
\end{gathered}
$$

\subsection{Final Goods Firms}

The key part of the model is the final goods sector where inventories are held. Final goods firms combine intermediate goods with labor to produce output. There is a fixed cost involved for each firm when ordering intermediate goods. To minimize the average cost of ordering, firms opt to carry inventories to smooth ordering costs intertemporally according to an (S,s) rule. So final goods firms will be heterogenous in their inventory positions.

As in KT, a typical final goods firm produces output $y_{t}$ according to the production function,

$$
y_{t}=m_{t}^{\theta_{m}} n_{t}^{\theta_{n}}
$$

where $n_{t}$ denotes labor and $m_{t}$ denotes intermediate goods input. Following KT, the fixed order cost is paid in labor units. Denoting $x_{t}$ as the size of an order, the total cost of an 
order is then given by $P_{t} x_{t}+\varepsilon_{t} W_{t}$, where $P_{t}$ is the relative price of intermediate goods, $\varepsilon_{t}$ is the fixed cost measured in labor units, so $\varepsilon_{t} W_{t}$ is the fixed cost of placing an order. Following the existing (S,s) policy literature (e.g., Caballero and Engel, 1999), $\varepsilon_{t}$ is assumed to be independently and identically distributed across time and firms, with the cumulative distribution function $F(\varepsilon)$. This distribution has a finite support in the positive domain with upper bound $\bar{\varepsilon}$. Denoting $s_{t}$ as the existing inventory level carried over from the last period, the law of motion for inventory accumulation is given by

$$
s_{t+1}=s_{t}+x_{t}-m_{t} .
$$

As in KT, there are storage costs involved in holding inventories. The storage cost is measured by final goods and proportional to the level of inventories, $\sigma_{t} s_{t+1} .{ }^{5}$ The aggregate state of the economy relevant to a firm is denoted by $\Omega_{t}=\left\{A_{t}, K_{t}, I_{t-1}, \mu_{t}\right\}$, which includes the aggregate technology shock $A_{t}$, the capital stock, and the lagged aggregate investment $I_{t-1}$, plus the distribution of firms' existing inventory stocks $\mu_{t}$. Given the firm-level state $\left\{s_{t}, \varepsilon_{t}\right\}$ and the aggregate state $\Omega_{t}$, the value function of a firm can be denoted by $V\left(s_{t}, \varepsilon_{t}, \Omega_{t}\right)$ or $V_{t}\left(s_{t}, \varepsilon_{t}\right)$ for short.

A final goods firm's profit maximization problem is to solve

$V_{t}\left(s_{t}, \varepsilon_{t}\right)=\max _{m_{t}, n_{t}, s_{t+1}, x_{t}}\left\{m_{t}^{\theta_{m}} n_{t}^{\theta_{n}}-\sigma_{t} s_{t+1}-P_{t} x_{t}-W_{t}\left(n_{t}+\varepsilon_{t} \mathbf{1}_{x_{t} \neq 0}\right)+\beta E_{t} \frac{\Lambda_{t+1}}{\Lambda_{t}} V_{t+1}\left(s_{t+1}, \varepsilon_{t+1}\right)\right\}$

subject to equation (17) and the following non-negativity constraints:

$$
\begin{aligned}
& s_{t+1} \geq 0 \\
& m_{t} \geq 0 \\
& n_{t} \geq 0,
\end{aligned}
$$

where $\mathbf{1}_{x_{t} \neq 0}$ in the objective function is an index function, which equals 1 if an order is placed in period $t$ and zero otherwise. The solution to (18) is a set of sequences, $n_{t}\left(s_{t}, \varepsilon_{t}\right), x_{t}\left(s_{t}, \varepsilon_{t}\right)$, $m_{t}\left(s_{t}, \varepsilon_{t}\right)$, and $s_{t+1}\left(s_{t}, \varepsilon_{t}\right)$. Notice that it may be optimal for a firm not to produce in period $t$ with $m_{t}=0$ and $n_{t}=0$.

\footnotetext{
${ }^{5}$ Since intermediate-good inventory $s_{t+1}$ shares the same growth trend with the order of intermediate goods $x_{t}$, and since total storage cost must be comparable to the value of intermediate-goods order $P_{t} x_{t}$, we must allow $\sigma_{t}$ to share the same trend in intermediate-goods price $P_{t}$.
} 


\subsection{Competitive Equilibrium}

A competitive general equilibrium is a set of aggregate quantities for households and intermediate goods firms, $\left\{C_{t}, N_{t}, X_{t}, K_{t+1}, L_{t}, e_{t}, I_{t}\right\}$, market prices, $\left\{\eta_{t}, P_{t}, W_{t}, \Lambda_{t}\right\}$, firm level quantities for final goods firms, $\left\{n_{t}\left(s_{t}, \varepsilon_{t}\right), x_{t}\left(s_{t}, \varepsilon_{t}\right), m_{t}\left(s_{t}, \varepsilon_{t}\right), s_{t+1}\left(s_{t}, \varepsilon_{t}\right)\right\}$, and the distribution of firms' inventory stocks, $\left\{\mu_{t+1}\right\}$, such that households maximize utilities, firms maximize profits, and all markets clear. Namely, a general equilibrium is characterized by the following conditions:

1. $C_{t}, N_{t}$ and $\Lambda_{t}$ satisfy equations (4) and (5).

2. $X_{t}, K_{t+1}, L_{t}, e_{t}, \eta_{t}, I_{t}$ satisfy equations (7), and (11) to (15).

3. $\left\{n_{t}\left(s_{t}, \varepsilon_{t}\right), x_{t}\left(s_{t}, \varepsilon_{t}\right), m_{t}\left(s_{t}, \varepsilon_{t}\right), s_{t+1}\left(s_{t}, \varepsilon_{t}\right)\right\}$ solves (18).

4. Labor market clears

$$
N_{t}=L_{t}+\iint\left[n_{t}(s, \varepsilon)+\varepsilon \mathbf{1}_{x(s, \varepsilon) \neq 0}\right] d \mu_{t} d F .
$$

5. Intermediate goods market clears

$$
X_{t}=\iint x_{t}(s, \varepsilon) d \mu_{t} d F \text {. }
$$

6. Final goods market clears

$$
C_{t}+I_{t}=\iint y_{t}(s, \varepsilon) d \mu_{t} d F,
$$

where $y_{t}(s, \varepsilon)=m_{t}^{\theta_{m}} n_{t}^{\theta_{n}}-\sigma_{t} s_{t+1}(s, \varepsilon)$ is the production level of a final goods firm with inventory level $s$ and fixed order $\operatorname{cost} \varepsilon$.

7. The evolution of inventory stocks across firms is characterized by

$$
\mu_{t+1}(S)=\iint \mathbf{1}_{s_{t+1}(s, \varepsilon) \leq S} d \mu_{t} d F,
$$

where $\mu_{t+1}(S) \equiv \operatorname{Pr}\left[s_{t+1} \leq S\right]$ denotes the cumulative distribution function of inventory stocks across final goods firms in period $t+1$, and $\mathbf{1}_{s_{t+1}(s, \varepsilon) \leq S}$ is an index function.

\section{Characterization of Inventory Decision Rules}

The above discussions suggest that as long as we can analytically solve for each individual final goods firm's decision rules, $\left\{n_{t}\left(s_{t}, \varepsilon_{t}\right), x_{t}\left(s_{t}, \varepsilon_{t}\right), m_{t}\left(s_{t}, \varepsilon_{t}\right), s_{t+1}\left(s_{t}, \varepsilon_{t}\right)\right\}$, the general 
equilibrium can then be characterized in a tractable manner. The purpose of this section is to show that the competitive equilibrium can be described by a system of closed-form nonlinear difference equations and thus solvable by standard techniques available in the representative-agent DSGE literature.

We call firms that are placing orders in period $t$ "active firms" and those not placing orders "inactive firms". A final goods firm's inventory decision rule can be characterized by a cutoff strategy: placing an order if $\varepsilon_{t} \leq \varepsilon_{t}^{*}\left(s_{t}\right)$ and remaining inactive if $\varepsilon_{t}>\varepsilon_{t}^{*}\left(s_{t}\right)$.

Proposition 1 Denoting an active firm's optimal level of intermediate goods input by $m_{0, t}$ and the optimal inventory stock carried over to the next period by $s_{1, t+1}$, a final goods firm's optimal decision rules for intermediate goods demand $\left(m_{t}\right)$, labor demand $\left(n_{t}\right)$, and inventory holdings $\left(s_{t+1}\right)$ are given by

$$
\begin{gathered}
m_{t}=\left\{\begin{array}{c}
m_{0 t} \quad \text { if } \varepsilon_{t} \leq \varepsilon_{t}^{*}\left(s_{t}\right) \\
m_{t}\left(s_{t}\right) \quad \text { if } \varepsilon_{t}>\varepsilon_{t}^{*}\left(s_{t}\right)
\end{array}\right. \\
n_{t}=\left\{\begin{array}{c}
\left(\frac{\theta_{n}}{W_{t}}\right)^{\frac{1}{1-\theta_{n}}} m_{0 t}^{\frac{\theta_{m}}{1-\theta_{n}}} \quad \text { if } \varepsilon_{t} \leq \varepsilon_{t}^{*}\left(s_{t}\right) \\
\left(\frac{\theta_{n}}{W_{t}}\right)^{\frac{1}{1-\theta_{n}}} m\left(s_{t}\right)^{\frac{\theta_{m}}{1-\theta_{n}}} \quad \text { if } \varepsilon_{t}>\varepsilon_{t}^{*}\left(s_{t}\right)
\end{array}\right. \\
s_{t+1}=\left\{\begin{array}{c}
s_{1, t+1} \\
\text { if } \varepsilon \leq \varepsilon_{t}^{*}\left(s_{t}\right) \\
s_{t}-m_{t}\left(s_{t}\right) \quad \text { if } \varepsilon>\varepsilon_{t}^{*}\left(s_{t}\right),
\end{array}\right.
\end{gathered}
$$

where $\left\{m_{0, t}, s_{1, t+1}\right\}$ are and must be state-independent, i.e., independent of the firm's existing inventory stock $s_{t}$ and the history of firm-specific cost shocks $\varepsilon_{t}$.

Proof. See Appendix A.

The inventory decision rule (28) implies that (i) all firms that decide to order intermediate goods in period $t$ (i.e., firms with small enough cost shocks) will replenish their inventories to the same level and thus carry the same amount of inventories forward into the next period regardless of their individual history; and (ii) all firms that have placed their last order in period $t-j$ will have the same existing inventory stock at the beginning of period $t$ regardless of their history. The same logic applies to intermediate goods demand and labor demand since these variables depend on $s_{t}$. Therefore, firms are distinguished only by the time since their last order of intermediate goods was made. This property greatly simplifies the analysis 
and permits exact aggregation of final goods firms' decision rules. But because inactive firms' decisions are state-dependent, we need to characterize the distribution of firms based on the time since their last order was made.

In anticipation of the results, assume that there are finite types of final goods firms distinguished by their inventory holdings at the start of the period, $s_{t}$. We can divide all firms into vintage groups $j=1,2, \ldots$, where $j$ is a positive integer. For example, $s_{j, t}$ denotes the inventory level at the beginning of period $t$ for firms that placed their last order in period $t-j$, and analogously $s_{j+1, t+1}$ denotes the inventory level at the start of period $t+1$ for firms that placed their last order in period $t-j$. However, $s_{j+1, t+1} \leq s_{j, t}$ because of inventory depletion, unless a new order is placed.

As equation (28) suggests, a firm will eventually run out of stock if it has not ordered for a sufficiently long period of time due to consecutive bad shocks. Let $J$ be the biggest possible value of $j$ such that $s_{J, t}>0$ in period $t$. This means that if some firms have not ordered for $J+1$ periods (or longer), they will have zero inventory in period $t$, so $s_{J+k, t}=0$ for all $k \geq 1$. We can group those firms with zero inventory into the same vintage group and label this group as vintage $J+1$. The fraction of vintage $j$ firms in the total population is denoted by $\omega_{j, t}$. Obviously, $\sum_{j=1}^{J+1} \omega_{j, t}=1$.

Hence, the distribution of inventory stocks across firms is discrete. At the start of each period $t$, there exists a fraction $\omega_{j, t}$ of firms with inventory level $s_{j, t}$. The distribution $\omega_{j, t}$ evolves according to the following simple mechanism. In period $t$, firms will place an order if and only if the fixed cost facing them is below the threshold $\varepsilon_{t}^{*}\left(s_{j, t}\right)$, or $\varepsilon_{j, t}^{*}$ for short. For these active firms, their inventory level will be adjusted immediately to $s_{1, t+1}$ after placing an order. So the total number of firms who have just placed an order in period $t$ and hence have inventory stock $s_{1, t+1}$ in period $t+1$ is given by

$$
\omega_{1, t+1}=\sum_{j=1}^{J+1} F\left(\varepsilon_{j t}^{*}\right) \omega_{j t},
$$

which is a discrete version of equation (25).

On the other hand, for each vintage $j$, there are $\left[1-F\left(\varepsilon_{j, t}^{*}\right)\right] \omega_{j, t}$ number of firms that do not order in period $t$. These firms evolve according to

$$
\omega_{j+1, t+1}=\left[1-F\left(\varepsilon_{j, t}^{*}\right)\right] \omega_{j, t} \text { for } j=1,2, \ldots, J-1 .
$$

The total fraction of firms with zero inventories at the start of period $t+1$ can consist of 
both vintage $J$ firms and vintage $J+1$ firms (notice that a firm in vintage $J+1$ will remain in that way if it does not order):

$$
\omega_{J+1, t+1}=\left[1-F\left(\varepsilon_{J, t}^{*}\right)\right] \omega_{J, t}+\left[1-F\left(\varepsilon_{J+1, t}^{*}\right)\right] \omega_{J+1, t} .
$$

The graphical presentation of the evolution of the cross-sectional distribution of firms in our model is analogous to that of Thomas (2002, p.516, Figure 1).

Since there are $J+1$ types of firms and each type has a unique cutoff, the next step is to determine vintage $j$ firms' inventory stock $s_{j, t}(j=1,2, \ldots, J+1)$, inputs of intermediate goods $m_{j, t}(j=0,1,2, \ldots, J)$, and the associated cutoff $\varepsilon_{j, t}^{*}(j=1,2, \ldots, J+1) .{ }^{6}$ Once we have determined $m_{j, t}$, we can then determine employment using equation (27) and the output level using production function. The complication involved is that all of these variables depend on the value functions of active firms and inactive firms.

Proposition 2 Given the state of the aggregate economy $\Omega_{t}$, the system of equations to jointly determine the following set of $3(J+1)+1$ variables, $\left\{\left\{s_{j, t+1}\right\}_{j=1}^{J+1},\left\{m_{j, t}\right\}_{j=0}^{J},\left\{\varepsilon_{j, t}^{*}\right\}_{j=1}^{J+1}, V_{t}^{a}\right\}$, is a set of value functions and firms' choices given by the following $3(J+1)+1$ equations:

$$
\begin{gathered}
V_{t}^{a}=R_{t} m_{0 t}^{\theta}-\sigma_{t} s_{1, t+1}-P_{t}\left(m_{0, t}+s_{1, t+1}\right)+ \\
\beta E_{t} \frac{\Lambda_{t+1}}{\Lambda_{t}}\left[V_{t+1}^{a}+P_{t+1} s_{1, t+1}-W_{t+1} \int \min \left\{\varepsilon, \varepsilon_{1, t+1}^{*}\right\} d F(\varepsilon)\right] \\
V_{t}^{a}+P_{t} s_{j, t}-W_{t} \varepsilon_{j, t}^{*}=R_{t} m_{j, t}^{\theta}-\sigma_{t} s_{j+1, t+1}+ \\
\beta E_{t} \frac{\Lambda_{t+1}}{\Lambda_{t}}\left[V_{t+1}^{a}+P_{t+1} s_{j+1, t+1}-W_{t+1} \int \min \left(\varepsilon, \varepsilon_{j+1, t+1}^{*}\right) d F(\varepsilon)\right], \quad j=1,2, \ldots J \\
V_{t}^{a}+P_{t} s_{J+1, t}-W_{t} \varepsilon_{J+1, t}^{*}=\beta E_{t} \frac{\Lambda_{t+1}}{\Lambda_{t}}\left[V_{t+1}^{a}-W_{t+1} \int \min \left(\varepsilon, \varepsilon_{J+1, t+1}^{*}\right) d F(\varepsilon)\right] \\
\theta R_{t} m_{j, t}^{\theta-1}+\sigma_{t}= \\
\beta E_{t} \frac{\Lambda_{t+1}}{\Lambda_{t}}\left[F\left(\varepsilon_{j+1, t+1}^{*}\right) P_{t+1}+\left(1-F\left(\varepsilon_{j+1, t+1}^{*}\right)\right) \theta R_{t+1} m_{j+1, t+1}^{\theta-1}\right], \quad j=0,1, \ldots, J-1 \\
s_{J+1, t+1}=0
\end{gathered}
$$

\footnotetext{
${ }^{6}$ Recall that $s_{J+1, t}=0$ and $m_{J+1, t}=0$. Firms with zero inventories also have a different cutoff, $\varepsilon_{J+1, t}^{*}$, in period $t$. This is why we let the index of cutoff run up to $J+1$.
} 


$$
\begin{gathered}
\theta R_{t} m_{0 t}^{\theta-1}=P_{t} \\
m_{j t}=s_{j t}-s_{j+1 t+1}, \quad j=1,2, \ldots, J
\end{gathered}
$$

where $\theta=\frac{\theta_{m}}{1-\theta_{n}}$ and $R_{t}=\left(1-\theta_{n}\right)\left(\frac{\theta_{n}}{W_{t}}\right)^{\frac{\theta_{n}}{1-\theta_{n}}}$.

Proof. See Appendix B.

Equation (32) is the value function of active firms in period $t$ with zero beginning-period inventories. Equations (33) and (34) are the value functions of inactive firms $\left(V_{j, t}^{n}\right)$ in vantage $j=1,2, \ldots, J+1$. In both equations, we have substituted $V_{j, t}^{n}$ with $V_{t}^{a}+P_{t} s_{j, t}-W_{t} \varepsilon_{j, t}^{*}$ using the cutoff equation (58) and the relation $V_{j, t}^{a}=V_{t}^{a}+P_{t} s_{j, t}$. Equations (37) and (38) are the policy functions for material input $m_{j, t}, j=0,1,2, \ldots, J$.

Equations (35) and (36) are the optimality conditions for choosing the next-period inventory stock $s_{j+1, t+1},(j=0,1,2, \ldots, J)$. In particular, equation $(36)$ is based on the definition for vantage $J+1$ and equation (35) is the Euler equation for intertemporal trade-off between the marginal cost of increasing inventories today and the marginal benefit of having more inventories tomorrow.

Specifically, when $j=0$, the left-hand side (LHS) of equation (35) equals $P_{t}+\sigma_{t}$ (based on equation (37)), which is the active firm's marginal cost of increasing the inventory stock by placing a new order: for each unit of additional inventories the firm pays $P_{t}$ to order and $\sigma_{t}$ to store the goods. The right-hand side (RHS) of equation (35) is the marginal gain of increasing the inventory stock. After ordering, the firm becomes a vintage $j=1$ firm in the next period. It has a probability $F\left(\varepsilon_{1, t+1}^{*}\right)$ of placing a new order and in such a case one additional unit of inventories will save the firm by $P_{t+1}=\frac{\partial V_{t+1}^{a}\left(s_{1, t+1}\right)}{\partial s_{1, t+1}}$ in ordering cost in period $t+1$. There is a probability $\left(1-F\left(\varepsilon_{1 t+1}^{*}\right)\right)$ that the firm will not order, in which case one additional unit of inventories generates $\theta R_{t+1} m_{1, t+1}^{\theta-1}$ units of profits. Equation (35) thus states that the optimal inventory level for an active firm $\left(s_{1, t+1}\right)$ must be such that it makes the benefits and costs equal in the margin.

When $j=1,2, \ldots, J-1$, the LHS of equation (35) is the marginal cost of carrying one additional unit of inventories forward for an inactive firm of vintage $j$. Increasing the inventory stock by one unit (without ordering) reduces the firm's operating revenue by $\theta R_{t} m_{j t}^{\theta-1}$ units and incurs $\sigma$ units of storage costs. On the other hand, the RHS is the benefit of having one additional unit of inventories available in the next period. With 
probability $F\left(\varepsilon_{j+1, t+1}^{*}\right)$ the firm will place a new order, in which case one additional unit of existing inventories can reduce the ordering cost by $P_{t+1}$. With probability $1-F\left(\varepsilon_{j+1 t+1}^{*}\right)$, this firm will not order and in such a case one additional unit of inventories can increase the firm's operating revenue by $\theta R_{t+1} m_{j+1 t+1}^{\theta-1}$ units.

\section{Steady State}

\subsection{The System of Aggregate Equations}

Denoting the aggregate variables by capital letters, we have a dynamic system consisting $4(J+1)+15$ variables:

$$
V_{t}^{a},\left\{\varepsilon_{j t+1}^{*}\right\}_{j=1}^{J+1},\left\{s_{j t}\right\}_{j=1}^{J+1},\left\{m_{j t}\right\}_{j=0}^{J},\left\{\omega_{j t}\right\}_{j=1}^{J+1}, C_{t}, N_{t}, X_{t}, S_{t}, M_{t}, L_{t}, e_{t}, \eta_{t}, I_{t}, P_{t}, W_{t}, R_{t}, \Lambda_{t}, K_{t}
$$

Among these variables, 14 are aggregate variables and $4(J+1)+1$ are firm-specific variables pertaining to inventory distributions. To solve for the competitive general equilibrium, we thus need $4(J+1)+15$ equations, which are listed below.

Labor market clearing implies

$$
N_{t}=L_{t}+\sum_{j=0}^{J-1} n_{j t} \omega_{j+1 t+1}+n_{J t}\left[1-F\left(\varepsilon_{J t}^{*}\right)\right] \omega_{J t}+\sum_{j=1}^{J+1} \omega_{j t} \int_{\varepsilon<\varepsilon_{j t}^{*}} \varepsilon d F(\varepsilon)
$$

where $n_{j t}=\left(\frac{\theta_{n}}{W_{t}}\right)^{\frac{1}{1-\theta_{n}}} m_{j t}^{\frac{\theta_{m}}{1-\theta_{n}}}$ for $j=0,1,2, \ldots, J$. The aggregate inventory at the beginning of period $t$ is

$$
S_{t}=\sum_{j=1}^{J+1} \omega_{j, t} s_{j, t}
$$

The total intermediate goods input is

$$
M_{t}=\sum_{j=0}^{J-1} m_{j t} \omega_{j+1 t+1}+m_{J t}\left[1-F\left(\varepsilon_{J t}^{*}\right)\right] \omega_{J t} .
$$

Intermediate goods market clearing requires

$$
X_{t}=S_{t+1}+M_{t}-S_{t}
$$


final goods market clearing implies

$$
C_{t}+I_{t}=Y_{t} \equiv \sum_{j=0}^{J-1} y_{j, t} \omega_{j+1, t+1}+y_{J, t}\left[1-F\left(\varepsilon_{J, t}^{*}\right)\right] \omega_{J, t}
$$

where $y_{j, t}=R_{t} m_{j, t}^{\theta} /\left(1-\theta_{n}\right)-\sigma_{t} s_{j+1, t+1}$, with $s_{J+1, t+1}=0$. In the intermediate goods firm's profit function, $R_{t}$ is defined by

$$
R_{t}=\left(1-\theta_{n}\right)\left(\frac{\theta_{n}}{W_{t}}\right)^{\frac{\theta_{n}}{1-\theta_{n}}}
$$

In addition, we have the first-order conditions for households in equations (4) and (5), and the first-order conditions for intermediate goods firms in equations (7), and (11)-(15). These together constitute 14 equations. The remaining $4(J+1)+1$ equations come from equations (29) to (38).

\subsection{Steady-State Distributions}

We detrend all variables in the model by the long-run growth trend of technology. A steady state in the detrended model is an equilibrium without aggregate uncertainty (i.e., $A_{t}=\bar{g}^{t} \bar{A}$ and $\Delta_{t}=\bar{\Delta}$ ), in which all detrended aggregate variables and the distribution of inventories are constant over time. We label those detrended variables with tilde " ". Since $\sigma_{t}$ share the same growth trend with intermediate-goods price $P_{t}$, we can redefine $\sigma_{t}=\tilde{\sigma} \bar{P}_{t}$, where $\bar{P}_{t}$ is the growth trend in $P_{t}$. Under the assumptions that $\varphi^{\prime}(1)=\varphi(1)=0$ for adjustment costs and $e=1$ for the capacity utilization rate in the steady state, our model has the same steady state as in the KT model (if there is no long-run growth, i.e. $\bar{g}=1$ ). Hence, these assumptions facilitate comparisons between the results in our model and the existing literature. $^{7}$

The detailed steps for solving the steady state, especially the steady-state distribution of inventories, are provided in Appendix C. The key is to determine the relative price of intermediate goods $\tilde{P}$. Given $\tilde{P}$, we can solve for the steady-state wage $\tilde{W}$ using equation (15) and the value of $\tilde{R}$. Then equations (29)-(38) can be used to solve for $\left\{\tilde{V}^{a},\left\{\varepsilon_{j}^{*}\right\}_{j=1}^{J+1},\left\{\tilde{s}_{j}\right\}_{j=1}^{J+1},\left\{\tilde{m}_{j}\right\}_{j=0}^{J},\left\{\omega_{j}\right\}_{j=1}^{J+1}\right\}$. Given these firm-level variables, the aggregate variables can be solved easily using equations (39)-(44).

\footnotetext{
${ }^{7}$ Having a positive steady state growth in the technology and assuming $e<1$ in the steady state do not affect our results significantly.
} 
Calibration and Estimation. The fixed order cost shock is assumed to follow a uniform distribution with support $[0, \bar{\varepsilon}]$, as in KT. We partition the model's parameter space $\Theta$ into two subsets. The first subset $\Theta_{1}$ includes only the parameters that affect the steady state. This parameter set is given by $\Theta_{1}=\left\{\beta, \tau, \alpha, \theta_{m}, \theta_{n}, \delta, \tilde{\sigma}, \bar{\varepsilon}\right\}$, which can be calibrated by the steady-state aggregate relations (or the model's first moments). All parameters in $\Theta_{1}$ are common between our model and the KT model, so we can set their values according to the calibration method in KT. In addition, we also fix the value of the long-run growth rate of TFP $(\bar{g})$ according to the quarterly utilization-adjusted TFP series in Fernald (2009), which is $\bar{g}=1.0021$. Table 1 summarizes the calibrated parameter values. ${ }^{8}$

[Table 1 is about here]

The second subset of parameters $\Theta_{2}$ is specific to our inventory model and these parameters do not affect the steady-state ratios and the distribution of firms' inventory stocks. They affect only the business-cycle dynamics of the model (or higher moments). This second parameter set is given by $\Theta_{2}=\left\{\chi, \gamma, \tilde{\varphi}, \rho_{g}, \rho_{T}, \rho_{\Delta}, \sigma_{g}, \sigma_{T}, \sigma_{\Delta}\right\}$, where $\chi$ is the habit formation parameter, $\gamma$ is the elasticity parameter in the depreciating function $\delta\left(e_{t}\right), \tilde{\varphi} \equiv \varphi^{\prime \prime}(1)$ is the elasticity parameter regarding investment adjustment cost in the steady state, and the remaining parameters in $\Theta_{2}$ are related to the shock processes. We will use the simulated method of moments to estimate $\Theta_{2}$ in the next section.

Under the calibrated parameter values for $\Theta_{1}$, the steady-state distributions of inventoryholding firms in our model are reported in Table 2. Since $\bar{g}$ has little effect on the model's steady state, our model should be able to replicate the steady state of the KT model even though we use a new solution method in this paper entirely different from KT's numerical method. Indeed, Table 2 shows that our results are very similar to the results reported by Khan and Thomas (2007a, Table 2). If we set $\bar{g}=0$, then we can replicate the results of KT exactly up to the third digit. In Appendix D, we discuss the accuracy of our solution method in more details. ${ }^{9}$

Using the words of KT, Table 2 shows that firms are distributed over six levels of inventories at the start of the period, reflecting six vintage groups. This vintage distribution is in columns labeled from 1 to 6 , while the first column (labeled active firms) represents

\footnotetext{
${ }^{8}$ The calibrated values for $\bar{\varepsilon}$ and $\tau$ are slightly different from those in the KT model, since our model contains a long-run trend $\bar{g}>0$. But the results are very similar.

${ }^{9}$ The minor difference may be due to numerical approximations. KT adopted a cubic spline approximation for solving the value functions of firms, while we compute the value functions recursively by a set of closedform nonlinear equations.
} 
those firms from each of these six groups that undertake inventory adjustment prior to production. The inventory level selected by all adjusting (active) firms is 1.652 in the steady state. Firms that adjusted their inventory holdings in the last period (those in column 1) begin the current period with 1.129 units of the intermediate good and a low probability of adjustment, $F\left(\varepsilon_{1}^{*}\right)=0.033$. Because inventory holdings decline with the time since the last order, firms are willing to accept larger adjustment costs as they move from vintage 1 across the distribution to vintage 6 . The existence of fixed order costs implies that the adjustment probability is less than one for all vintage groups. In fact, even among the 0.028 firms that begin the period with no inventory, only 78.1 percent adjust prior to production. The remainder forego production in the current period and await lower adjustment costs.

[Table 2 is about here]

\section{The Business-Cycle Implications of Inventories}

\subsection{Control Model}

To examine whether inventories are important for the business cycle, we estimate our model and compare its predictions with a control model in which there are no inventories (i.e., $\bar{\varepsilon}=0) .{ }^{10}$ Since final goods firms are identical in the control model because they do not carry inventories, the problem of the control model can also be cast as a representative-agent or social planner's problem: ${ }^{11}$

$$
\max _{C_{t}, e_{t}, I_{t}, M_{t}, N_{t}, L_{t}, K_{t+1}} E_{0} \sum_{t=0}^{\infty} \beta^{t}\left[\Delta_{t} \log \left(C_{t}-\chi C_{t-1}\right)+\tau\left(1-N_{t}-L_{t}\right)\right]
$$

subject to

$$
\begin{gathered}
C_{t}+I_{t} \leq M_{t}^{\theta_{m}} N_{t}^{\theta_{n}} \\
M_{t}=A_{t}\left(e_{t} K_{t}\right)^{\alpha} L_{t}^{1-\alpha} \\
K_{t+1}=\left(1-\delta\left(e_{t}\right)\right)+\left[1-\varphi\left(\frac{I_{t}}{I_{t-1}}\right)\right] I_{t} .
\end{gathered}
$$

\footnotetext{
${ }^{10}$ As pointed out by KT, when $\bar{\varepsilon}=0$, final goods firms can order the exact quantity of intermediate goods to use in the current production without delivery costs. In this case, firms opt not to carry any inventories.

${ }^{11}$ Notice that our control model is not the same as the control model in KT except in the steady state, since we allow multiple shocks and real frictions.
} 


\subsection{Estimation}

As in KT, gross domestic product (GDP) in this paper is measured as the sum of aggregate final goods output plus the value of intermediate goods inventory investment based on the value-added approach:

$$
G D P_{t}=C_{t}+I_{t}+P_{t}\left(X_{t}-M_{t}\right)
$$

where $P_{t}$ is the relative price of inventories.

In the presence of aggregate shocks, our model can be solved by log-linearization around the steady state. We generate artificial time series from the model, apply the HP filter to both model-generated data and the real world data, and use simulated method of moments to estimate the structural parameters in $\Theta_{2}$. In particular, the estimator $\hat{\Theta}_{2}$ solves

$$
\hat{\Theta}_{2}=\arg \min _{\Theta_{2}}\left[\Psi^{\text {Data }}-\Psi^{\text {Model }}\left(\Theta_{2}\right)\right]^{\prime} W_{T}\left[\Psi^{\text {Data }}-\Psi^{\text {Model }}\left(\Theta_{2}\right)\right]
$$

where $\Psi^{\text {Data }}$ and $\Psi^{\text {Model }}\left(\Theta_{2}\right)$ are the business-cycle moments implied by the actual data and the model, respectively; and $W_{T}$ is a weighting matrix. For simplicity, we assume that $W_{T}$ is an identity matrix. Notice that the structural parameters in the control model $\left(\Theta_{2}\right)$ are re-estimated by the simulated method of moments, so our comparative analysis puts the two models on an equal base.

To construct the data moments $\Psi^{\text {Data }}$, five quarterly U.S. time series are used, including real GDP $\left(G D P_{t}\right)$, real consumption $\left(C_{t}\right)$, real fixed investment $\left(I_{t}\right)$, aggregate inventoryto-sales ratio $\left(S Y_{t}\right)$, and hours worked $\left(N_{t}\right) \cdot{ }^{12}$ All data series and model-generated series are HP filtered. We target 14 business-cycle moments: the variances and the first order auto-covariances of the five data series, as well as the 4 covariances of $\left\{C_{t}, I_{t}, S Y_{t}, N_{t}\right\}$ with respect to GDP.

[Table 3 is about here]

Table 3 (top panel) reports the estimated parameter values for the parameter set $\Theta_{2}$ in the baseline model and the control model (numbers in parentheses are the asymptotic standard errors computed according to Ingram and Lee, 1991). ${ }^{13}$ The estimated parameter values are reasonable and consistent with much of the existing literature. All the estimation

\footnotetext{
${ }^{12}$ These series are directly taken from Wen (2011), which can be downloaded from http://www.aeaweb.org/aej/mac/data/2010-0095_data.zip

${ }^{13}$ We simulate 5000 periods for each time series in our estimation.
} 
values, except the investment adjustment cost parameter $\tilde{\varphi}$ and the persistence parameter for transitory technology shock $A_{t}^{T}$, are precisely estimated with high statistical significance. The habit formation parameter $\chi$ is about 0.5, the investment adjustment cost parameter is about 0.4 (with a large standard error), and the depreciation elasticity of capacity utilization $\gamma$ is about 1.7. Regarding the exogenous shocks, the technology growth shock is serially correlated with $\rho_{g}=0.25$, the transitory technology shock is less persistent than assumed in the literature with $\rho_{T}=0.39$, and the demand shock $\Delta_{t}$ is highly persistent with $\rho_{\Delta}=0.98$. The high persistence of the demand shock is consistent with the existing literature that emphasizes demand shocks (e.g., Wen, 2004).

[Table 4 is about here]

Table 4 reports the predicted business-cycle moments $\Psi^{\text {Model }}\left(\Theta_{2}\right)$ based on the estimated parameters $\hat{\Theta}_{2}$ (for both the inventory model and the control model, respectively). The table has four panels - top-left, top-right, bottom-left, and bottom-right panel, corresponding respectively to four moments - STD, relative STD, correlation with GDP, and autocorrelations of seven macro variables. In each panel, the first column pertains to data, the second column to the inventory model, and the third column to the control model. The inventory model matches the data quite well in all moments for all variables, better than those of the control model in general (note that the control model's parameters are re-estimated by the method of moments to yield the best fit). For example, the last column of the top-right panel shows that the control model over-predicts the relative standard deviations of consumption, investment, and employment by a significant margin compared to the inventory model.

The supreme performance of the inventory model over the control model is also reflected in the minimum distance between the model and the data moments captured by the objective function in equation (50). Specifically, the minimum distance metric is 0.1744 for the inventory model and 0.7834 for the control model, suggesting that allowing for inventories can substantially improve the empirical fit of a DSGE model, even though the DSGE (control) model already features multiple aggregate shocks and several realistic frictions (such as habit formation, investment adjustment costs, and capacity utilization) that can improve its empirical fit.

That inventories further improve the fit of a DSGE model is also evident in the KT model. For example, if we enrich the original KT model by multiple shocks $\left\{A_{t}^{P}, A_{t}^{T}, \Delta_{t}\right\}$ (but without real frictions such as habit formation, investment adjustment costs, and variable 
capacity utilization), and estimate this model's parameters by our solution methods, the minimum distance metric is 0.6010 for the KT model and 1.2910 for its counterpart control model. The minimum distances for all different models considered are summarized in Table 5. Obviously, the KT model with inventories matches the data moments much better than its own respective control model, but not significantly better than our control model without inventories. Therefore, our inventory model is strongly preferred not only to the respective control model without inventories but also to the KT model with inventories in terms of goodness of fit. For this reason, we use our inventory model as a laboratory for examining the contributions of inventories in the business cycle.

To sum up, the main messages from this section are that (i) inventories can improve the empirical fit of a DSGE model (regardless of the KT model or our model), and (ii) adding multiple shocks and real frictions can further improve the empirical fit of an inventory model. However, these findings cannot tell us whether inventories amplify the business cycle or not, which is the question we study in Section ?? below.

[Table 5 is about here]

\subsection{Variance Decomposition}

In addition to parameter estimations, our solution method allows us to conduct variance decomposition and impulse response analyses. Khan and Thomas (2007b) emphasize the importance of technology shocks and the (S,s) inventory adjustment in explaining the inventory cycle. But their conclusion is based on a model in which inventories do not matter for aggregate fluctuations. Here we re-examine their findings based on a model in which inventories matter. We found that demand shocks are more important than technology shocks in explaining the short-run aggregate fluctuations of the U.S. economy.

Table 6 reports variance decomposition of aggregate output in our inventory model (left panel) and in the multiple-shock augmented KT model (right panel). In each panel, we report the contributions of the three aggregate shocks, $\left\{A_{t}^{P}, A_{t}^{T}, \Delta_{t}\right\}$, to total output variance. First, the right panel confirms the analysis in Khan and Thomas (2007b) that technology shocks are more important than demand shocks in explaining output movements. For example, in the short-run horizon of 1-8 quarters, demand shocks explain only about 33\%-42\% of output variations in the KT model. In the long-run horizon of 40 quarters, they explain less than $23 \%$ of output fluctuations. However, in our model where inventories matter (left panel), demand shocks explain more than $60 \%$ of output variations in the very short run. 
Even in the long run horizon of 40 quarters, the contribution of demand shocks still remains about $35 \%$.

[Table 6 is about here]

Moreover, if we compare each inventory model with its counterpart control model, we found that allowing for inventories reduces the contribution of demand shocks in the multipleshock KT model, whereas it raises the contribution of demand shocks in our model. This difference is closely related to the following analysis regarding whether inventories matter or not for amplifying the business cycle.

\section{Contributions of Inventories to Aggregate Volatility}

The conventional wisdom has it that inventories destabilize the economy because inventory investment is procyclical and more volatile than sales. However, this conventional wisdom is challenged by Khan and Thomas (2007a) and Wen (2011) using general-equilibrium analyses. This general-equilibrium literature shows that when sales are endogenous, procyclical inventory investment has insignificant impact on production (Khan and Thomas, 2007a) or may even significantly stabilize the economy (Wen, 2011) because inventories can reduce the volatility of aggregate demand more than amplifying the volatility of aggregate supply. KT and Wen's findings are different from each other because they use models with different microfoundations for the existence of inventories - inventories exist in the KT model because of fixed order costs and they exist in Wen's model because of stockout-avoidance motives.

In this paper, we found that inventories amplify the volatility of aggregate output significantly in a (S,s) inventory model, in contrast to the finding of Khan and Thomas (2007a). To study the amplification effect of inventory to aggregate fluctuations, we compare our baseline inventory model to its control model in which there are no inventories. Table 7 (left panel) reports the predicted STD of aggregate output with and without inventories, as well as the STD of other variables. ${ }^{14}$ Obviously, inventories amplify the fluctuation of aggregate output by as much as $\frac{0.0192}{0.0162} \approx 19 \%$. This amplification effect derives mostly from a more volatile fixed capital investment and employment in the inventory model. Table 7 shows that both investment and employment are significantly more volatile with inventories than without. Consistent with the finding of Khan and Thomas (2007a), the volatility of final sales (and

\footnotetext{
${ }^{14}$ To make the comparison consistent, we set the parameters in the control models to the same values in the inventory model, as in the analysis of KT (2007a).
} 
consumption) is reduced by inventories, but the reduction is not significant enough to offset the higher volatility of total output due to a higher volatility of both capital investment and inventory investment.

In contrast, the right panel of Table 7 shows that in the KT model (enriched by the three aggregate shocks), the volatility of aggregate output remains essentially the same regardless of inventories. In particular, compared with its counterpart control model without inventories, the KT inventory model decreases the volatility of output by less than $1 \%$. The main reason for this irrelevance result in the KT model is that the excess volatility introduced by procyclical inventory investment is exactly offset by the reduced variability of final sales (mostly capital investment), as shown in the columns labeled KT and KT Control, where the volatility of capital investment is reduced by nearly $60 \%$ and that of final sales is reduced by $22 \%$ with inventories as opposed to without. However, in our model (the columns labeled Baseline and Control), such a crowding-out (or trade-off) effect of inventory investment volatility on capital investment volatility is substantially mitigated so that capital investment is more volatile with inventories than without. This increased volatility of investment and labor also brings our model into a closer conformity to the data than the KT model even though the KT model is already augmented and improved with two additional aggregate shocks.

[Table 7 is about here]

Why do inventories destabilize output production in our model but not in the KT model? Our analyses below show that variable capacity utilization and investment adjustment costs are key.

Effects of Capacity Utilization. Consider capacity utilization first. Since inventories amplify both technology shocks and demand shocks in our model, we discuss only the case of technology shocks so as to make the results comparable to the original Khan and Thomas (2007a) model where only technology shocks exist. The intuition under demand shocks are analogous.

A positive technology shock reduces the prices of intermediate goods. This induces not only the active final goods firms to increase the size of their orders but also some of the inactive firms to place orders. This incentive for building up inventory stocks to reduce future fixed order costs increases the aggregate demand for intermediate goods more than in the case with the control model. However, with fixed capacity utilization, the only way to increase intermediate output is to expand labor input because capital is predetermined. 
Thus, a sharp increase in the production of intermediate goods to satisfy inventory demand is possible if labor is diverted from the final goods sector to the intermediate goods sector so that the increase of labor input in the final goods sector is less than it would otherwise be. This reallocation of labor reduces the volatility of final goods production and thus offsets the positive contribution of inventory investment to GDP volatility, generating the KT result.

With variable capacity utilization, however, intermediate goods production can be increased without necessarily increasing labor input in this sector, regardless of inventories. So the general-equilibrium effect uncovered by KT-namely, labor is diverted from the final goods sector to the intermediate goods sector - is not an issue. That is, a rising inventory demand for intermediate goods can be met by a higher rate of capacity utilization even without labor reallocation. Given this, even if labor were reallocated from the final goods sector to the intermediate goods sector to the same extent as in the KT model, it would not completely offset the positive effect of inventory investment on GDP volatility.

In other words, because capacity utilization is a "local factor" of production, it does not compete with the final-goods sector for resources. Hence, the general-equilibrium trade-off between inventory investment and final sales in the original KT model is attenuated. This suggests that our result should continue to hold even in more general $(\mathrm{S}, \mathrm{s})$ models (such as a model in which both the final goods sector and the intermediate goods sector use capital in production), precisely because capacity utilization is a local input. Our finding thus suggests that inventories can still be significantly destabilizing to the economy even though they may reduce the volatility of final sales in general equilibrium (as Table 7 shows).

KT argue that the existence of capital is essential for their results because inventories in their model can significantly increase the volatility of GDP when capital is eliminated from the model or capital's share in output is significantly reduced. Given that capacity utilization effectively reduces capital's share by making labor more variable (Wen, 1998), our results may seem to be already anticipated by KT. This is not entirely true, however. For example, reducing capital share in the KT model increases the steady state inventory-tosales ratio significantly while introducing capacity utilization has no effect on the steady state inventory-to-sales ratio. In addition, reducing capital share increases the relative volatility of fixed investment but allowing for capacity utilization reduces it. Given that the KT model with realistic capital share already implies too large a volatility of fixed capital investment, capacity utilization brings the KT model into closer conformity with the data while reducing capital share does the opposite.

We can also show that the destabilizing effect of inventories on GDP gets stronger as the 
variability of capacity utilization increases. Suppose we set $\chi=\tilde{\varphi}=0$, so that only capacity utilization remains operative in our model. In Table 8, the first row represents the values of $\gamma$ and the second row the relative volatility of the inventory model to the control model. As the value of $\gamma$ increases, it becomes more costly to adjust capacity utilization rate, so the destabilizing role of inventories diminishes.

[Table 8 is about here]

Effects of Investment Adjustment Costs (IAC). IAC imply that firms want to smooth out capital investment over time to avoid the adjustment costs. In this case inventories will play a more strategic role for final goods firms to reduce fixed order costs than when there are no IAC, because the total demand of final goods is now expected to persist for a longer period of time after a technology (or preference) shock. Given the lowered intermediate goods price after the technology shock and the anticipated persistence in final sales in the future, firms will opt to increase inventory investment sharply, more so than they would otherwise without IAC. This increased procyclicality and volatility of inventory investment significantly raises the overall volatility of GDP. So the dampening effect of labor reallocation from the final goods sector to the intermediate goods sector is no longer sufficient to offset the positive effect of inventory investment on GDP volatility when IAC exist. ${ }^{15}$ The lower panel in Table 8 confirms that larger IAC imply a higher output volatility ratio, similar to the effects of capacity utilization. ${ }^{16}$

Impulse Responses. To help understand why demand shocks are more important in our model than in the KT model, we shut down habit formation, capacity utilization, and investment adjustment costs in our baseline model and compare the impulse response function of this simpler model (labeled "KT Model" in Figure 1) with our baseline model under demand shocks.

The left panel in Figure 1 reveals that our model (solid line) dominates the KT model (dashed line) in explaining the business cycle - because our model can generate hump-shaped persistence in almost all aggregate variables under demand shocks whereas the KT model cannot. Most importantly, the right panel in the figure reveals that inventory investment in the KT model (dashed line) is countercyclical (its correlation with output is negative) and not sufficiently volatile, whereas in our baseline model (solid line) it is strongly procyclical

\footnotetext{
${ }^{15}$ The intuition is similar under persistent demand shocks. A positive demand shock implies that the demand for final goods will be persistently high, so firms have incentives to increase inventory investment, and this increase is more in the presence of IAC than without.

${ }^{16}$ Although habit formation $(\chi)$ is estimated to be significant, we do not find habit formation important in allowing inventories to amplify the business cycle.
} 
(its correlation with output is positive) and far more volatile (as in the data). Since a countercyclical inventory investment is inconsistent with the data, the impulse response analysis explains why the KT model "dislikes" demand shocks whereas our model favors demand shocks when being estimated by the method of moments. ${ }^{17}$

[Figure 1 is about here]

\section{Conclusion}

Fisher and Hornstein (2000) explicitly point out in a general-equilibrium model without capital that $(\mathrm{S}, \mathrm{s})$ inventory policies do not necessarily generate inventory behaviors consistent with the data. Khan and Thomas (2007a) show in a general-equilibrium model with capital that even if inventory investment can comove with sales and orders are more volatile than sales, $(\mathrm{S}, \mathrm{s})$ inventory policies do not amplify the business cycle.

This paper argues that to correctly assess the role of inventories in the business cycle, it is preferable to start with a model that can quantitatively match both the inventory behavior and the general business-cycle pattern of the data. Therefore, we build on the existing literature by providing a full-fledged general-equilibrium $(\mathrm{S}, \mathrm{s})$ inventory model that can closely match the observed business-cycle facts, including aggregate inventory behaviors. We estimate our model by the method of moments. We find that when the model is in line with the observed business-cycle moments and aggregate inventory behaviors, $(\mathrm{S}, \mathrm{s})$ type inventory behaviors do appear to be important in helping us understand the business cycle. In particular, we find that $(\mathrm{S}, \mathrm{s})$ inventory policies can significantly amplify the business cycle.

An independent contribution of our paper is that we provide a tractable method to solve $(\mathrm{S}, \mathrm{s})$ inventory policies in a general-equilibrium framework with both idiosyncratic and aggregate shocks. Our solution method enables us to estimate the model's structural parameters that are key to business-cycle dynamics around the steady state. Since our solution method can handle large state space with as many aggregate state variables as in a representative $\mathrm{RBC}$ model, we are able to answer some questions the existing $(\mathrm{S}, \mathrm{s})$ inventory literature has not been able to fully address. ${ }^{18}$

\footnotetext{
${ }^{17}$ The results are similar if we use the fully estimated KT model as shown in previous Tables. Also, under technology shocks, our model also performs significantly better than the KT model.

${ }^{18}$ Appendix D provide direct comparisons between the accuracy of our solution method with that used in KT (2007a). Our new solution method obviously allows more state variables if they come in as scalars from the representative household or the representative firm. It is less clear how the same method could be used in the presence of new state variables arising from the inclusion of additional heterogeneity - e.g., persistent firm-specific demand or productivity shocks or micro-founded capital adjustment costs. It is possible that
} 
However, as illustrated by Wang and Wen (2009) and Wen (2011), different incentives for inventory demands can have dramatically different implications for the (de)stabilizing role of inventories. A similar point is also made by Chang, Hornstein, and Sarte (2009). Therefore, conclusions drawn from the (S,s)-type inventory models do not generalize to other types of inventory models. In the end, which inventory models can better characterize inventory behavior is an empirical question open for further studies.

the method could be expanded to handle such additional heterogeneity following the approach described in the final section of King and Thomas (2006); however, that remains to be seen. In addition, the method we advocate may not always handle the occasionally binding non-negativity constraints on inventories correctly when the system is sufficiently away from steady state. 


\section{Appendix}

\section{A Proof of Proposition 1}

Proof. We solve the firm's problem in several steps.

1. We solve the firm's labor demand by

$$
\theta_{n} m_{t}^{\theta_{m}} n_{t}^{\theta_{n}-1}=W_{t}
$$

which yields

$$
n_{t}=\left(\frac{\theta_{n}}{W_{t}}\right)^{\frac{1}{1-\theta_{n}}} m_{t}^{\frac{\theta_{m}}{1-\theta_{n}}}
$$

Substituting this solution into the profit function gives

$$
m_{t}^{\theta_{m}} n_{t}^{\theta_{n}}-W_{t} n_{t} \equiv R_{t} m_{t}^{\theta}
$$

where $\theta=\frac{\theta_{m}}{1-\theta_{n}}$ and

$$
R_{t}=\left(1-\theta_{n}\right)\left(\frac{\theta_{n}}{W_{t}}\right)^{\frac{\theta_{n}}{1-\theta_{n}}}
$$

2. Define $V_{t}^{a}\left(s_{t}\right)$ as the value function of an active firm that places an order in period $t$ (excluding the fixed order cost) and $V_{t}^{a}\left(s_{t}\right)-\varepsilon_{t} W_{t}$ as the firm's value function including the fixed order cost. Define $V_{t}^{n}\left(s_{t}\right)$ as the value function of an inactive firm that decides not to order intermediate goods in period $t$. With these notations, the final goods producer's problem in equation (18) becomes

$$
V_{t}\left(s_{t}, \varepsilon_{t}\right)=\max \left\{V_{t}^{a}\left(s_{t}\right)-W_{t} \varepsilon_{t}, V_{t}^{n}\left(s_{t}\right)\right\} .
$$

Define $\bar{V}_{t}\left(s_{t}\right)=\int V_{t}\left(s_{t}, \varepsilon\right) d F(\varepsilon)$ as the average (expected) value of a firm with inventory stock $s_{t}$. So by definition we can write the Bellman equation for $V_{t}^{a}\left(s_{t}\right)$ as

$$
V_{t}^{a}\left(s_{t}\right)=\max _{x_{t}, s_{t+1}} R_{t}\left(s_{t}+x_{t}-s_{t+1}\right)^{\theta}-\sigma_{t} s_{t+1}-P_{t} x_{t}+\beta E_{t} \frac{\Lambda_{t+1}}{\Lambda_{t}} \bar{V}_{t}\left(s_{t+1}\right) .
$$

The value function for an inactive firm (with $x_{t}=0$ ) can be written as

$$
V_{t}^{n}\left(s_{t}\right)=\max _{s_{t+1}} R_{t}\left(s_{t}-s_{t+1}\right)^{\theta}-\sigma_{t} s_{t+1}+\beta E_{t} \frac{\Lambda_{t+1}}{\Lambda_{t}} \bar{V}_{t}\left(s_{t+1}\right) .
$$


3. Obviously, $V_{t}^{a}\left(s_{t}\right) \geq V_{t}^{n}\left(s_{t}\right)$, since $x_{t}=0$ is always a possible solution for the problem defined in (56). Comparing $V_{t}^{a}\left(s_{t}\right)-W_{t} \varepsilon_{t}$ and $V_{t}^{n}\left(s_{t}\right)$ for any given inventory level $s_{t}$, it is easy to see that there exists a cutoff value for the fixed cost, $\varepsilon_{t}^{*}$, such that

$$
V_{t}^{a}\left(s_{t}\right)-W_{t} \varepsilon_{t}^{*}=V_{t}^{n}\left(s_{t}\right) .
$$

The above equation defines the cutoff as an implicit function of the firm's inventory stock $s_{t}$. So we can denote $\varepsilon_{t}^{*}=\varepsilon_{t}^{*}\left(s_{t}\right)$. A firm will place an order $\left(x_{t}>0\right)$ if and only if $\varepsilon_{t} \leq \varepsilon_{t}^{*}\left(s_{t}\right)$.

4. For a firm that decides to place an order, the first-order condition with respect to $x_{t}$ is

$$
\theta R_{t} m_{t}^{\theta-1}=P_{t}
$$

which solves for the optimal input level for an active firm, $m_{0 t}=\left(\frac{P_{t}}{\theta R_{t}}\right)^{\frac{1}{\theta-1}}$. Note that the solution is independent of the existing inventory stock and the fixed cost shock; i.e., it is state independent. By equation (52), the optimal labor demand is also independent of $\left\{s_{t}, \varepsilon_{t}\right\}$. We denote these state-independent variables as $m_{0 t}$ and $n_{0 t}$. The first-order condition with respect to inventory holding $s_{t+1}$ is

$$
\theta R_{t} m_{0 t}^{\theta-1}+\sigma_{t}=\beta E_{t} \frac{\Lambda_{t+1}}{\Lambda_{t}} \frac{\partial \bar{V}_{t+1}\left(s_{t+1}\right)}{\partial s_{t+1}}
$$

Combining the previous two equations, we have

$$
P_{t}+\sigma_{t}=\beta E_{t} \frac{\Lambda_{t+1}}{\Lambda_{t}} \frac{\partial \bar{V}_{t+1}\left(s_{t+1}\right)}{\partial s_{t+1}}
$$

This implies that the optimal level of inventories for an active firm, $s_{t+1}$, is also stateindependent (i.e., it depends only on the aggregate variables and not on the firm's history). That is, all firms that decide to place an order in period $t$ will replenish their inventory stocks to the same level regardless of their individual histories. We denote $s_{1, t+1}$ as the optimal level of inventory stock carried over to period $t+1$ by active firms.

5. We now turn to inactive firms which do not place orders in period $t$ (i.e., $\varepsilon_{t}>\varepsilon_{t}^{*}$ ). The first-order condition for $s_{t+1}$ in the problem (57) is given by

$$
\theta R_{t}\left(s_{t}-s_{t+1}\right)^{\theta-1}+\sigma_{t}=\beta E_{t} \frac{\Lambda_{t+1}}{\Lambda_{t}} \frac{\partial \bar{V}_{t+1}\left(s_{t+1}\right)}{\partial s_{t+1}}+\pi_{t}
$$


where $\pi_{t}$ is a Lagrangian multiplier associated with the non-negative constraint on $s_{t+1}$. Notice that in this case $m_{t}=s_{t}-s_{t+1}$ because $x_{t}=0$. The above equation defines the decision rules for intermediate goods input $m_{t}=m_{t}\left(s_{t}\right)$ and inventory holdings $s_{t+1}=s_{t}-m\left(s_{t}\right)$. By equation (52), labor demand can be written as $n_{t}=n_{t}\left(s_{t}\right)$. The decision rules at the firm level are summarized by equations (26)-(28).

\section{B Proof of Proposition 2}

Proof. First of all, by definition we have $s_{J+1, t+1}=0$. Also, for vintage- $j$ firms that do not order in period $t$, we have $m_{j, t}=s_{j, t}-s_{j+1, t+1}$ for $j=1,2, \ldots, J$. These give us $J+1$ equations that correspond to equations (36) and (38) in Proposition 2.

To prove equation (32), consider the value function of an active firm with vintage $j$ :

$$
V_{t}^{a}\left(s_{j, t}\right)=\max _{m_{0, t}, s_{1, t+1}}\left\{R_{t} m_{0, t}^{\theta}-\sigma_{t} s_{1, t+1}-P_{t}\left(m_{0, t}+s_{1, t+1}-s_{j, t}\right)+\beta E_{t} \frac{\Lambda_{t+1}}{\Lambda_{t}} \bar{V}_{t+1}\left(s_{1, t+1}\right)\right\}
$$

where $\bar{V}_{t+1}\left(s_{1, t+1}\right)$ is the expected value function with respect to idiosyncratic shock $\varepsilon$ evaluated at $s_{1, t+1}$. Since the term $P_{t} s_{j, t}$ on the right-hand side (RHS) does not affect the optimal choices (because $s_{j, t}$ is predetermined), we can define a new value function (for active firms) that is independent of $j$ :

$$
V_{t}^{a}=\max _{m_{0, t}, s_{1, t+1}}\left\{R_{t} m_{0, t}^{\theta}-\sigma_{t} s_{1, t+1}-P_{t}\left(m_{0, t}+s_{1, t+1}\right)+\beta E_{t} \frac{\Lambda_{t+1}}{\Lambda_{t}} \bar{V}_{t+1}\left(s_{1, t+1}\right)\right\} .
$$

That is, $V_{t}^{a}$ equals $V_{t}^{a}\left(s_{j, t}\right)$ evaluated at $s_{j, t}=0$. Now $V_{t}^{a}\left(s_{j, t}\right)$ can be rewritten as

$$
V_{t}^{a}\left(s_{j t}\right) \equiv V_{j, t}^{a}=V_{t}^{a}+P_{t} s_{j t}
$$

According to equation (58), the value function of inactive firms can be rewritten as

$$
V_{j, t}^{n}=V_{t}^{a}+P_{t} s_{j, t}-W_{t} \varepsilon_{j, t}^{*}
$$

For the maximization problem in equation (64), the first-order condition with respect to $m_{0, t}$ and $s_{1, t+1}$ are given, respectively, by

$$
\theta R_{t} m_{0 t}^{\theta-1}=P_{t}
$$




$$
P_{t}+\sigma_{t}=\beta E_{t} \frac{\Lambda_{t+1}}{\Lambda_{t}} \frac{\partial \bar{V}_{t+1}\left(s_{1, t+1}\right)}{\partial s_{1, t+1}}
$$

where equation (67) corresponds to equation (37) in Proposition 2. Now we need to determine the derivative, $\frac{\partial \bar{V}_{t}\left(s_{j, t}\right)}{\partial s_{j, t}}$. Notice that by equations (55) and (58), the expected value function $\bar{V}_{t}\left(s_{j, t}\right)$ is given by

$$
\bar{V}_{t}\left(s_{j, t}\right)=F\left(\varepsilon_{j, t}^{*}\right) V_{t}^{a}\left(s_{j, t}\right)+\left[1-F\left(\varepsilon_{j, t}^{*}\right)\right] V_{t}^{n}\left(s_{j, t}\right)-W_{t} \int_{\varepsilon<\varepsilon_{j, t}^{*}} \varepsilon d F(\varepsilon)
$$

Thus,

$\frac{\partial \bar{V}_{t}\left(s_{j, t}\right)}{\partial s_{j, t}}=F\left(\varepsilon_{j, t}^{*}\right) \frac{\partial V_{t}^{a}\left(s_{j, t}\right)}{\partial s_{j, t}}+\left[1-F\left(\varepsilon_{j, t}^{*}\right)\right] \frac{\partial V_{t}^{n}\left(s_{j, t}\right)}{\partial s_{j, t}}+\left[V_{t}^{a}\left(s_{j, t}\right)-\varepsilon_{j, t}^{*}-V_{t}^{n}\left(s_{j, t}\right)\right] f\left(\varepsilon_{j, t}^{*}\right) \frac{\partial \varepsilon_{j, t}^{*}}{\partial s_{j, t}} W_{t}$.

By equation (58), the last term is zero, so we have

$$
\frac{\partial \bar{V}_{t}\left(s_{j t}\right)}{\partial s_{j t}}=F\left(\varepsilon_{j t}^{*}\right) \frac{\partial V_{t}^{a}\left(s_{j t}\right)}{\partial s_{j t}}+\left[1-F\left(\varepsilon_{j t}^{*}\right)\right] \frac{\partial V_{t}^{n}\left(s_{j t}\right)}{\partial s_{j t}}
$$

The task of computing $\frac{\partial \bar{V}_{t}\left(s_{j, t}\right)}{\partial s_{j, t}}$ now reduces to calculating the partial derivatives $\frac{\partial V_{t}^{a}\left(s_{j t}\right)}{\partial s_{j t}}$ and $\frac{\partial V_{t}^{n}\left(s_{j t}\right)}{\partial s_{j t}}$. According to equation (65), we immediately have ${ }^{19}$

$$
\frac{\partial V_{j, t}^{a}}{\partial s_{j, t}}=P_{t}
$$

To obtain $\frac{\partial V_{t}^{n}\left(s_{j t}\right)}{\partial s_{j t}}$ in equation (71), we need to consider the value function of the inactive firms of vintage $j$. For $j=1,2, \ldots J$, we have

$$
V_{t}^{n}\left(s_{j, t}\right)=\max _{m_{j, t}, s_{j+1, t+1}}\left\{R_{t} m_{j, t}^{\theta}-\sigma_{t} s_{j+1, t+1}+\beta E_{t} \frac{\Lambda_{t+1}}{\Lambda_{t}} \bar{V}_{t+1}\left(s_{j+1, t+1}\right)\right\}
$$

where $m_{j, t}=s_{j, t}-s_{j+1, t+1}$. The first-order condition with respect to $s_{j+1, t+1}(j=1,2, \ldots, J)$ is given by

$$
\theta R_{t} m_{j t}^{\theta-1}+\sigma_{t}=\beta E_{t} \frac{\Lambda_{t+1}}{\Lambda_{t}} \frac{\partial \bar{V}_{t+1}\left(s_{j+1, t+1}\right)}{\partial s_{j+1, t+1}}
$$

\footnotetext{
${ }^{19}$ This equation can also be obtained by applying the envelop theorem to equation (63)
} 
By the envelop theorem we have

$$
\frac{\partial V_{t}^{n}\left(s_{j, t}\right)}{\partial s_{j, t}}=\theta R_{t} m_{j, t}^{\theta-1}
$$

Now, putting (72) and (75) into equation (71) gives

$$
\frac{\partial \bar{V}_{t}\left(s_{j, t}\right)}{\partial s_{j, t}}=F\left(\varepsilon_{j, t}^{*}\right) P_{t}+\left[1-F\left(\varepsilon_{j, t}^{*}\right)\right] \theta R_{t} m_{j, t}^{\theta-1} .
$$

Plugging this equation into (68) and (74), respectively, gives

$$
\begin{gathered}
P_{t}+\sigma_{t}=\beta E_{t} \frac{\Lambda_{t+1}}{\Lambda_{t}}\left[F\left(\varepsilon_{1, t+1}^{*}\right) P_{t+1}+\left[1-F\left(\varepsilon_{1, t+1}^{*}\right)\right] \theta R_{t+1} m_{j+1, t+1}^{\theta-1}\right] \\
\theta R_{t} m_{j t}^{\theta-1}+\sigma_{t}=\beta E_{t} \frac{\Lambda_{t+1}}{\Lambda_{t}}\left[F\left(\varepsilon_{j+1, t+1}^{*}\right) P_{t+1}+\left[1-F\left(\varepsilon_{j+1, t+1}^{*}\right)\right] \theta R_{t+1} m_{j+1, t+1}^{\theta-1}\right] .
\end{gathered}
$$

These two equations, together with equation (67), correspond to the $J+1$ equations in equation (35) in Proposition 2.

The remaining $J+2$ equations are related to $V_{t}^{a}$ and the cutoff $\varepsilon_{j, t}^{*}$ for $j=1,2, \ldots J+1$, which are determined by equation (66). We can use equation (66) to substitute out $V_{t}^{n}\left(s_{j, t}\right)$ in equation (69) to obtain

$$
\begin{aligned}
\bar{V}_{t}\left(s_{j, t}\right) & =\int_{\varepsilon \leq \varepsilon_{j t}^{*}}\left[V_{t}^{a}\left(s_{j t}\right)-W_{t} \varepsilon\right] d F(\varepsilon)+\int_{\varepsilon>\varepsilon_{j t}^{*}}\left[V_{t}^{a}\left(s_{j t}\right)-W_{t} \varepsilon_{j t}^{*}\right] d F(\varepsilon) \\
& =V_{t}^{a}\left(s_{j t}\right)-W_{t} \int \min \left\{\varepsilon, \varepsilon_{j t}^{*}\right\} d F(\varepsilon) \\
& =V_{t}^{a}+P_{t} s_{j t}-W_{t} \int \min \left\{\varepsilon, \varepsilon_{j t}^{*}\right\} d F(\varepsilon),
\end{aligned}
$$

where the third line comes from equation (65). Substituting the above equation for $\bar{V}_{t}\left(s_{j, t}\right)$ into equation (64) under the optimal choices gives equation (32) in Proposition 2. Using the relation (66) and the function $\bar{V}_{t}\left(s_{j+1, t+1}\right)$ defined in equation (79) to substitute out $V_{j, t}^{n}$ and $\bar{V}\left(s_{j+1, t+1}\right)$ in equation (73) under the optimal choices gives equations (33) and (34) in Proposition 2. These together give us $J+2$ additional equations. The total number of equations is thus $3(J+1)+1$ in Proposition 2 . 


\section{Steps for Solving Steady State}

Since our model contains a long-run trend, we need to detrend the model before solving the steady state. We denote the detrended variables as $\tilde{x}_{t}$. For those variables without trend, their notations remain the same.

We then solve the steady state of our inventory model in several steps: in steps 1 and 2, we list all the variables and the corresponding equations needed to solve for the variables; in steps 3 and 4, we illustrate how to recursively solve the steady state using the system of equations listed in steps 1 and 2 .

Step 1. We first list the equations needed to solve for the steady-state distributions

of final goods firms, taking as given the aggregate variables, $\{\tilde{P}, \tilde{W}, \tilde{R}\}$. Assume that the fixed order cost $\varepsilon$ follows the power distribution, $F(\varepsilon)=\left(\frac{\varepsilon}{\bar{\varepsilon}}\right)^{\kappa}$ with support $\varepsilon \in[0, \bar{\varepsilon}]$. The uniform distribution is a special case when $\kappa=1$. Given the power distribution, we have the relationship

$$
\int \min \left\{\varepsilon, \varepsilon^{*}\right\} d F(\varepsilon)=\left[1-\frac{1}{1+\kappa}\left(\frac{\varepsilon^{*}}{\bar{\varepsilon}}\right)^{\kappa}\right] \varepsilon^{*} .
$$

The distribution of firms can then be solved using the following system of $4(J+1)$ equations implied by those in Proposition 2 and the following relationship:

$$
\tilde{V}_{j, t}^{a}=\tilde{V}_{t}^{a}+\tilde{P}_{t} \tilde{s}_{j, t}, \quad j=1,2, \ldots, J
$$

First, using the steady-state relationship implied by equation (81), $\tilde{V}_{j}^{a}=\tilde{V}^{a}+\tilde{P} \tilde{s}_{j}$, we have

$$
\tilde{V}_{j}^{a}=\tilde{V}_{1}^{a}-\tilde{P}\left(\tilde{s}_{1}-\tilde{s}_{j}\right)
$$

where $\tilde{V}_{1}^{a}$ is determined by equations (32) and (81) as

$$
\tilde{V}_{1}^{a}=\tilde{R} \tilde{m}_{0}^{\theta}-\tilde{\sigma} \tilde{s}_{1}-\tilde{P} \tilde{m}_{0}+\beta\left[\tilde{V}_{1}^{a}-\tilde{W} \int \min \left\{\varepsilon, \varepsilon_{1}^{*}\right\} d F(\varepsilon)\right] .
$$

These $J+1$ equations can be used in determining $\tilde{V}_{j}^{a}, j=1,2, \ldots, J+1$.

Second, the following $J+1$ equations can be used in determining $\varepsilon_{j}^{*}, j=1,2, \ldots, J+1$. Equations (33) and (34) imply

$$
\tilde{V}_{j}^{a}-\tilde{W} \varepsilon_{j}^{*}=\tilde{R} \tilde{m}_{j}^{\theta}-\tilde{\sigma} \tilde{s}_{j+1}+\beta\left[\tilde{V}_{j+1}^{a}-\tilde{W} \int \min \left\{\varepsilon, \varepsilon_{j+1}^{*}\right\} d F(\varepsilon)\right], \text { for } j=1, \ldots, J
$$




$$
\tilde{V}_{J+1}^{a}-\tilde{W} \varepsilon_{J+1}^{*}=\beta\left[\tilde{V}_{J+1}^{a}-\tilde{W} \int \min \left\{\varepsilon, \varepsilon_{J+1}^{*}\right\} d F(\varepsilon)\right] .
$$

Third, from the first-order conditions for inventories, we have additional $J+1$ equations that can be used in determining $\tilde{s}_{j}$ for $j=1,2, \ldots, J+1$. Specifically, equations (35) and (36) imply

$$
\begin{gathered}
\theta \tilde{R} \tilde{m}_{j}^{\theta-1}+\tilde{\sigma}=\beta\left\{F\left(\varepsilon_{j+1}^{*}\right) \tilde{P}+\left[1-F\left(\varepsilon_{j+1}^{*}\right)\right] \theta \tilde{R} \tilde{m}_{j+1}^{\theta-1}\right\}, j=0,2, \ldots J-1 \\
\tilde{s}_{J+1}=0 .
\end{gathered}
$$

Finally, from the policy functions of input materials, the following $J+1$ equations can be used in determining $\tilde{m}_{j}, j=0,1,2, \ldots, J$. Equations (37) and (38) imply

$$
\begin{gathered}
\theta \tilde{R} \tilde{m}_{0}^{\theta-1}=\tilde{P}, \\
\tilde{m}_{j}=\tilde{s}_{j} / g_{2}-\tilde{s}_{j+1}, \quad j=1,2, \ldots J,
\end{gathered}
$$

where $g_{2}=\bar{g}^{\frac{1}{1-\alpha \theta_{m}}}$.

Step 2. Now, we solve for the aggregate variables $\{\tilde{W}, \tilde{R}\}$ as a function of the relative price of intermediate goods, $\tilde{P}$. By the first-order conditions of intermediate goods firms, equations (12) and (15), the real wage $\tilde{W}$ can be expressed as

$$
\tilde{W}=(1-\alpha) \tilde{P}\left(\frac{\tilde{K}}{\tilde{L}} / g_{1}\right)^{\alpha}
$$

where $g_{1}=\bar{g}^{\frac{\alpha \theta_{m}}{1-\alpha \theta_{m}}}, \frac{\tilde{K}}{\tilde{L}}=\left[\left(\frac{1}{\beta}-1+\delta\right) g_{1}^{\alpha} /(\alpha \tilde{P})\right]^{\frac{1}{\alpha-1}}$. Given $\tilde{W}$, the steady-state $\tilde{R}$ can be solved using equation (44).

Step 3. We now show how to recursively solve $\left\{\left\{\tilde{s}_{j}\right\}_{j=1}^{J+1},\left\{\tilde{m}_{j}\right\}_{j=0}^{J},\left\{\varepsilon_{j}^{*}\right\}_{j=1}^{J+1},\left\{\tilde{V}_{j}^{a}\right\}_{j=1}^{J+1}\right\}$ as functions of $\tilde{P}$ from the system of equations listed above. Equation (88) implies

$$
\tilde{m}_{0}=\left(\frac{\tilde{P}}{\theta \tilde{R}}\right)^{\frac{1}{\theta-1}}
$$


So given $\tilde{P}$ and $\left\{\tilde{s}_{1}, \varepsilon_{1}^{*}\right\}$ for vintage 1 firms, we can compute $\left\{\tilde{m}_{j}\right\}_{j=1}^{J},\left\{\tilde{s}_{j}\right\}_{j=2}^{J+1},\left\{\varepsilon_{j}^{*}\right\}_{j=2}^{J+1}$, and $\left\{\tilde{V}_{j}^{a}\right\}_{j=1}^{J+1}$ recursively below. Then we will use two additional constraints to obtain $\left(\tilde{s}_{1}, \varepsilon_{1}^{*}\right)$ at the end.

Equation (83) implies that $\tilde{V}_{1}^{a}$ is a function of $\left(\tilde{s}_{1}, \varepsilon_{1}^{*}\right)$ and $\tilde{P}$ :

$$
\tilde{V}_{1}^{a}=\frac{\tilde{R} \tilde{m}_{0}^{\theta}-\tilde{\sigma} \tilde{s}_{1}-\tilde{P} \tilde{m}_{0}-\beta \tilde{W} \int \min \left\{\varepsilon, \varepsilon_{1}^{*}\right\} d F(\varepsilon)}{1-\beta} .
$$

From the recursive equation (86), we can compute $\tilde{m}_{1}$ in terms of $\tilde{m}_{0}^{\theta}$ and $\varepsilon_{1}^{*}$ :

$$
\tilde{m}_{1}=\left\{\frac{\theta \tilde{R} \tilde{m}_{0}^{\theta}+\tilde{\sigma}-\beta F\left(\varepsilon_{1}^{*}\right) \tilde{P}}{\beta\left[1-F\left(\varepsilon_{1}^{*}\right)\right] \theta \tilde{R}}\right\}^{\frac{1}{\theta-1}}
$$

From equations (89) and (82), $\tilde{s}_{2}$ and $\tilde{V}_{2}^{a}$ can be updated to

$$
\begin{gathered}
\tilde{s}_{2}=\tilde{s}_{1} / g_{2}-\tilde{m}_{1} \\
\tilde{V}_{2}^{a}=\tilde{V}_{1}^{a}-\tilde{P} \tilde{m}_{1} .
\end{gathered}
$$

Finally, from equation (84), we can solve for the cutoff $\varepsilon_{2}^{*}$ according to the following equation:

$$
\left[1-\frac{1}{1+\kappa}\left(\frac{\varepsilon_{2}^{*}}{\bar{\varepsilon}}\right)^{\kappa}\right] \varepsilon_{2}^{*}-\frac{\tilde{V}_{1}^{a}-\tilde{W} \varepsilon_{1}^{*}-\tilde{R} \tilde{m}_{1}^{\theta}+\tilde{\sigma} \tilde{s}_{2}-\beta \tilde{V}_{2}^{a}}{\beta \tilde{W}}=0 .
$$

Repeating the above steps will give us $\left\{\tilde{s}_{j}, \varepsilon_{j}^{*}, \tilde{m}_{j-1}, \tilde{V}_{j}^{a}\right\}$ for $j=2, \ldots, J+1$. That is, by equation (86), we can update $\tilde{m}_{j}$. By equation (89), we can compute $\tilde{s}_{j+1}$. Then we can use equation (82) to compute $\tilde{V}_{J+1}^{a}$. Finally, using equation (84), we can obtain $\varepsilon_{j+1}^{*}$.

Once we have finished the above recursive procedure, we still need two more equations to pin down $\tilde{s}_{1}$ and $\varepsilon_{1}^{*}$. Remember that we still have two additional equations that have not been used yet: equations (85) and (87). By equation (89) at $j=J$ and equation (87), we have

$$
\tilde{s}_{J}\left(\tilde{P}, \varepsilon_{1}^{*}, \tilde{s}_{1}\right)=\tilde{m}_{J}\left(\tilde{P}, \varepsilon_{1}^{*}, \tilde{s}_{1}\right)
$$

which yields one additional equation. For the other equation, notice that from previous recursive calculations, we have obtained $\tilde{V}_{J+1}^{a}\left(\tilde{P}, \varepsilon_{1}^{*}, \tilde{s}_{1}\right)$ and $\varepsilon_{J+1}^{*}\left(\tilde{P}, \varepsilon_{1}^{*}, \tilde{s}_{1}\right)$. Plugging them 
into equation (85) gives

$$
\tilde{V}_{J+1}^{a}-\tilde{W} \varepsilon_{J+1}^{*}=\beta\left[\tilde{V}_{J+1}^{a}-\tilde{W} \int \min \left\{\varepsilon, \varepsilon_{J+1}^{*}\right\} d F(\varepsilon)\right]
$$

which gives the other equation needed for solving $\left\{\varepsilon_{1}^{*}, s_{1}\right\}$. Therefore given $\tilde{P}$, equations (97) and (98) constitute two nonlinear equations that can be used to jointly solve for $\varepsilon_{1}^{*}$ and $\tilde{s}_{1}$.

Once we know the cutoffs, $\varepsilon_{1}^{*}, \varepsilon_{2}^{*}, \ldots \varepsilon_{J+1}^{*}$, the distribution $\left\{\omega_{j}\right\}$ can then be solved by evaluating equations (29) to (31) at steady state.

Step 4. Now we specify the final step to solve for $\tilde{P}$. According to equations (41) and (42), the total production of intermediate goods, given $\tilde{P}$, is

$$
\tilde{X}=\tilde{S}\left(1-1 / g_{2}\right)+\tilde{M}=\tilde{S}\left(1-1 / g_{2}\right)+\sum_{j=0}^{J-1} \tilde{m}_{j} \omega_{j+1}+\tilde{m}_{J}\left[1-F\left(\varepsilon_{J}^{*}\right)\right] \omega_{J} .
$$

Since the Euler equation for capital stock, (12), implies

$$
\alpha \tilde{P} \frac{\tilde{X}}{\tilde{K}}=\frac{1}{\beta}-(1-\delta) / g_{1}
$$

we can solve for $\tilde{K}$ as function of $\tilde{P}$. Since investment equals $\bar{\delta} \tilde{K}$, we can obtain $\tilde{I}=$ $\left[1-(1-\bar{\delta}) / g_{1}\right] \tilde{K}$. Also, from the household optimal condition of consumption (4), we can solve for aggregate consumption using

$$
\frac{1}{\tilde{C}} \tilde{W}=\tau
$$

According to equation (43), the aggregate production for final goods can be determined by

$$
\tilde{Y}=\sum_{j=0}^{J-1} \tilde{y}_{j} \omega_{j+1}+\tilde{y}_{J}\left[1-F\left(\varepsilon_{J}^{*}\right)\right] \omega_{J}
$$

where $\tilde{y}_{j}=\tilde{R} \tilde{m}_{j}^{\theta} /\left(1-\theta_{n}\right)-\tilde{\sigma} \tilde{s}_{j+1}$, for $j=0, \ldots, J$. Therefore, the final goods market clearing condition implies

$$
\tilde{Y}(\tilde{P})=\tilde{C}(\tilde{P})+\tilde{I}(\tilde{P}),
$$

which can be used to solve for $\tilde{P}$. 


\section{Accuracy of Our Solution Method}

To compare the accuracy of our solution method with that used by KT, we illustrate it from two aspects below.

(1). Unlike the Krusell-Smith algorithm used in Khan and Thomas (2007a), we approximate the distribution of firms by finite $(J+1)$ vintages as in Dotsey et al. (1999), as shown above in Appendix C. We choose a large enough value of $J$ such that the steady state of all aggregate variables under considerations converge. Table A1 below reports the steady-state values of aggregate variables for different values of $J$. As can be seen, when $J \geq 5$, the steady-state values converge. We thus set $J$ to be 5 in our paper. That is, we categorize the inventory firms into 6 vintage groups, which turns out identical to that assumed in Khan and Thomas (2007a).

[Table A1. is about here]

Table A2 reports the steady-state distribution of inventory firms. In particular, the firms in the fifth vintage group that adjusted their ordering of materials five periods before hold positive inventory stocks, but the level is 0.006. This means the non-negative constraints

$s_{j} \geq 0$ of these firms are not binding. Since the inventory stock $s_{j}$ is decreasing in $j$, we categorize all the firms with inactive time longer than 5 periods into the last group (group 6 ). These firms are treated as one with zero inventories (or with a binding constraint $s=0$ ). However, the last group actually consists of two type of firms: those with the constraint $s_{j} \geq 0$ frequently binding and those with exact zero inventory stocks. So an approximation error is involved here. However, we believe that our approximation does not lose accuracy because: (i) even though some firms in the last group may hold positive inventory stocks, the level is negligible (less than 0.006), so classifying them as zero-inventory firms is not unacceptable; (ii) the measure of these firms is very small - accounts less than $2.8 \%$ of total firms. In principle, we can increase the size of $J$ to shrink this approximation error further down to zero. These two points imply that the general equilibrium effects of the last vintage group's behaviors on the aggregate dynamics of our model is very limited.

[Table A2. is about here]

(2). To see that our method performs at least as well as that of Khan and Thomas (2007a), we first apply our method to replicate their results. Table A3 reports the steady-state 
distribution of inventory firms in the original KT model. As the table shows, the distribution implied by our solution method (numbers in bold) is very close to those reported by Khan and Thomas (2007a), the difference lies only in the third dismal digit. This comparison indicates that our solution method performs at least equally well compared with KT's numerical method, in the sense of characterizing the steady-state inventory distributions.

[Table A3. is about here]

Now we compare the business cycle moments obtained by log-linearization (our method) with those in KT's paper. Table A4 shows that the moments based on the two methods are very close to each other - differ only by the third dismal digit. This means the loglinearization does not cause loss in accuracy regarding the model's dynamics. In fact, we are free to use higher order approximations to further improve the solution accuracy if desired. In addition, the relative ratio of GDP volatility between inventory model and control model is 1.0158 in our method, that value in Khan and Thomas (2007a) is 1.0151. This means that our method yields identical predictions to KT's method regarding the amplification effect of inventory investments on the business cycle.

[Table A4. is about here]

Based on the above comparisons, we are confident that our tractable approach with loglinearization approximation performs as well as KT's numerical approach for characterizing both the steady state and the business cycle dynamics, but our method is much faster and can thus be easily applied to model estimations. 


\section{References}

[1] Blinder, A. 1981, Retail inventory behavior and business fluctuations, Brookings Papers on Economic Activity 12(2), 443-520.

[2] Blinder, A. and L. Maccini, 1991, Taking stock: A critical assessment of recent research on inventories, Journal of Economic Perspectives 5(1), 73-96.

[3] Caballero, R. and E. Engel, 1991, Dynamic (S, s) Economies, Econometrica, 59(6), 1659-1686.

[4] Caballero, R. and E. Engel, 1999, Explaining Investment Dynamics in U.S. Manufacturing: A Generalized (S,s) Approach, Econometrica 67(4), 783-826.

[5] Caplin, A., 1985, The variability of aggregate demand with $(\mathrm{S}, \mathrm{s})$ inventory policies, Econometrica 53, 1395-1410.

[6] Caplin, A. and J. Leahy, 1991, State-dependent pricing and the dynamics of output and prices, Quarterly Journal of Economics 106, 683-708.

[7] Chang, Y., A. Hornstein, and P. Sarte, 2009, On the employment effects of productivity shocks: The role of inventories, demand elasticity, and sticky prices, Journal of Monetary Economics 56(3), 328-343.

[8] Dotsey, M., R. King, and A. Wolman, 1999, State-dependent pricing and the general equilibrium dynamics of money and output, Quarterly Journal of Economics 114(2), 655-690.

[9] Fernald, J., 2009, A Quarterly Utilization-Adjusted Series on Total Factor Productivity, Federal Reserve Bank of San Francisco Working Paper.

[10] Fisher, J. and A. Hornstein, 2000, (S,s) inventory policies in general equilibrium, Review of Economic Studies 67(1), 117-145.

[11] Ingram, B. and B. Lee, 1991. Simulation estimation of time-series models, Journal of Econometrics 47(2-3), 197-205.

[12] Khan, A. and J. Thomas, 2007a, Inventories and the business cycle: An equilibrium analysis of (S,s) policies, American Economic Review 97(4), 1165-88. 
[13] Khan, A. and J. Thomas, 2007b, Explaining inventories: a business cycle assessment of the stockout avoidance and (S,s) motives, Macroeconomic Dynamics 11(5), 638-64.

[14] King R. and J. Thomas, 2006. Partial adjustment without apology, International Economic Review, 47(3), 779-809.

[15] Krusell, P. and A. Smith, 1998, Income and wealth heterogeneity in the macroeconomy, Journal of Political Economy, 106(5), 867-896.

[16] Miao, J. and P. Wang, 2013, A Q-Theory Model with Lumpy Investment, Economic Theory (forthcoming).

[17] Thomas, J., 2002, Is lumpy investment relevant for the business cycle?, Journal of Political Economy, 110(3), 508-534.

[18] Wang, P. and Y. Wen, 2009, Inventory accelerator in general equilibrium, Federal Reserve Bank of St. Louis Working Paper 2009-010A.

[19] Wen, Y., 1998, Capacity utilization under increasing returns to scale, Journal of Economic Theory, 81(1), 7-36.

[20] Wen, Y., 2004, What does it take to explain procyclical productivity?, Contributions To Macroeconomics 4(1), 1-38.

[21] Wen, Y., 2005, Understanding the inventory cycle, Journal of Monetary Economics 52, $1533-1555$.

[22] Wen, Y., 2011, Input and output inventory dynamics, American Economic Journal: Macroeconomics 3 (October), 181-212. 
Table 1. Calibrated Parameter Values in $\Theta_{1}$

\begin{tabular}{ccccccccc}
\hline \hline$\beta$ & $\tau$ & $\alpha$ & $\theta_{m}$ & $\theta_{n}$ & $\bar{\delta}$ & $\tilde{\sigma}$ & $\bar{\varepsilon}$ & $\bar{g}$ \\
0.984 & 2.250 & 0.374 & 0.499 & 0.328 & 0.017 & 0.012 & 0.240 & 1.0021 \\
\hline
\end{tabular}


Table 2. Steady-State Distribution of Inventory Firms

\begin{tabular}{lccccccc}
\hline \hline Vintage $(j)$ & Active firms & 1 & 2 & 3 & 4 & 5 & 6 \\
\cline { 2 - 7 } Distribution $\omega\left(s_{j}\right)$ & & 0.259 & 0.251 & 0.220 & 0.160 & 0.082 & 0.028 \\
Inventories $s_{j}$ & \multirow{2}{*}{1.652} & 1.129 & 0.693 & 0.346 & 0.105 & 0.006 & 0.000 \\
Fraction adjusting $F\left(\varepsilon_{j}^{*}\right)$ & & 0.033 & 0.124 & 0.271 & 0.485 & 0.730 & 0.781 \\
\hline
\end{tabular}


Table 3. Estimated Parameters in $\hat{\Theta}_{2}$

\begin{tabular}{cccccccccc}
\hline \hline & $\chi$ & $\tilde{\varphi}$ & $\gamma$ & $\rho_{g}$ & $\sigma_{g}$ & $\rho_{T}$ & $\sigma_{T}$ & $\rho_{\Delta}$ & $\sigma_{\Delta}$ \\
\hline Baseline & 0.4995 & 0.3963 & 1.7394 & 0.2509 & 0.0122 & 0.3908 & 0.0032 & 0.9843 & 0.0130 \\
& $(0.0081)$ & $(0.4342)$ & $(0.5665)$ & $(0.0274)$ & $(0.0009)$ & $(0.2914)$ & $(0.0017)$ & $(0.0206)$ & $(0.0008)$ \\
\multirow{4}{*}{ Control } & 0.5187 & 0.3714 & 1.1553 & 0.0138 & 0.0148 & 0.3226 & 0.0012 & 0.9958 & 0.0148 \\
& $(0.0829)$ & $(0.4698)$ & $(0.3340)$ & $(0.2588)$ & $(0.0034)$ & $(0.9403)$ & $(0.0187)$ & $(0.0382)$ & $(0.0017)$ \\
\hline
\end{tabular}


Table 4. Business-Cycle Moments $\Psi^{\text {Model }}$

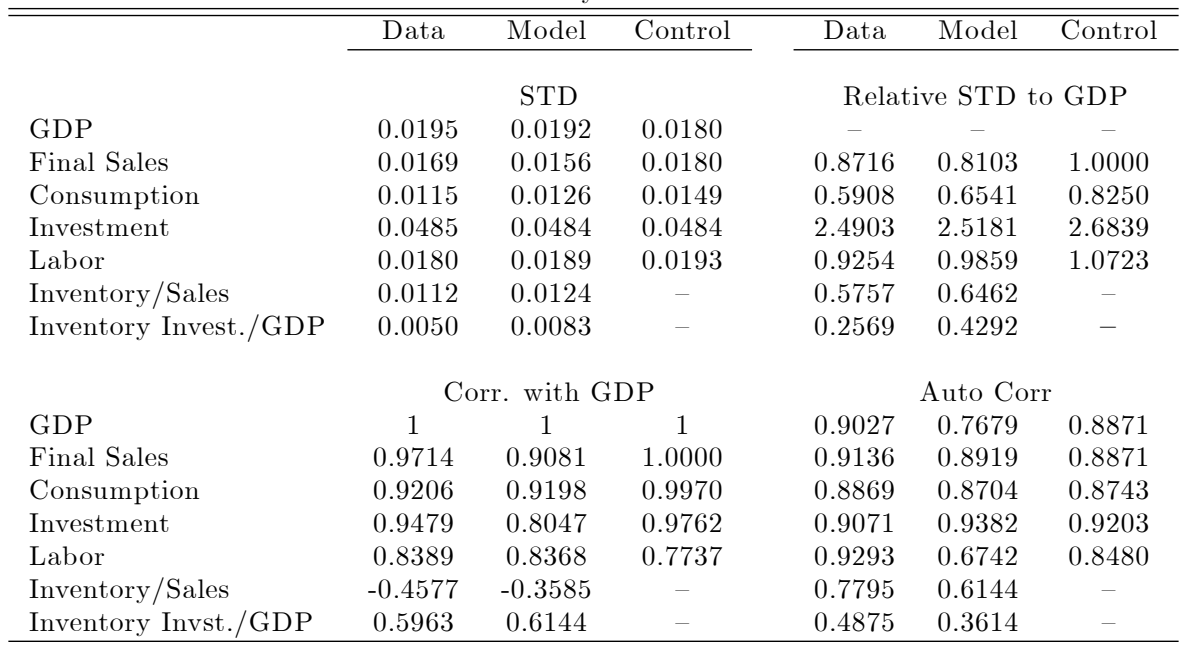


Table 5. Minimum Distance between Model \& Data

\begin{tabular}{ccccc}
\hline \hline & Our Inventory Model & Our Control Model & KT Inventory Model & KT Control Model \\
Min. Distance & 0.1744 & 0.7834 & 0.6010 & 1.2910 \\
\hline
\end{tabular}


Table 6. Output Variance Decomposition

\begin{tabular}{ccccccc}
\hline \hline & \multicolumn{3}{c}{ Our Model } & \multicolumn{3}{c}{ KT Model } \\
& $A_{t}^{P}$ & $A_{t}^{T}$ & $\Delta_{t}$ & $A_{t}^{P}$ & $A_{t}^{T}$ & $\Delta_{t}$ \\
\hline & & & & & & \\
$1 \mathrm{Q}$ & 10.8319 & 29.0954 & 60.0727 & 20.4405 & 46.5952 & 32.9644 \\
$4 \mathrm{Q}$ & 53.4297 & 3.9570 & 42.6134 & 40.4148 & 17.4622 & 42.1229 \\
$8 \mathrm{Q}$ & 55.1925 & 1.8427 & 42.9648 & 48.6908 & 10.3393 & 40.9699 \\
$40 \mathrm{Q}$ & 64.3276 & 0.4413 & 35.2310 & 73.6050 & 3.4030 & 22.9920 \\
\hline
\end{tabular}


Table 7. Predicted STD with/without Inventories

\begin{tabular}{lcccc}
\hline \hline & Baseline & Control & KT & KT Control \\
\hline Output & 0.0192 & 0.0162 & 0.0188 & 0.0189 \\
Final Sales & 0.0156 & 0.0162 & 0.0149 & 0.0189 \\
Consumption & 0.0126 & 0.0135 & 0.0133 & 0.0137 \\
Investment & 0.0483 & 0.0455 & 0.0492 & 0.1189 \\
Labor & 0.0189 & 0.0159 & 0.0207 & 0.0209 \\
\hline
\end{tabular}


Table 8. Sensitivity Analysis

\begin{tabular}{ccccccc}
\hline \hline$\gamma$ & 1.10 & 1.15 & 1.25 & 1.4 & 2.0 & 3.0 \\
$\left(\frac{\text { GDP volatility with inventory }}{\text { GDP volatility without inventory }}\right)$ & 1.46 & 1.34 & 1.21 & 1.13 & 1.05 & 1.02 \\
$\tilde{\varphi}$ & 0.1 & 0.5 & 1.0 & 1.5 & 2.0 & 3.0 \\
$\left(\frac{\text { GDP volatility with inventory }}{\text { GDP volatility without inventory }}\right)$ & 1.023 & 1.043 & 1.051 & 1.059 & 1.066 & 1.068 \\
\hline
\end{tabular}




\begin{tabular}{ccccccccc}
\hline \hline \multicolumn{8}{c}{ Table A1. The Steady State of Aggregate Variables } \\
\hline & $P$ & $C$ & $I$ & $Y$ & $S$ & $X$ & $M$ & $W$ \\
$J=4$ & 0.4218 & 0.2953 & 0.0307 & 0.3260 & 0.5489 & 0.3684 & 0.3670 & 0.6539 \\
$J=5$ & 0.4214 & 0.2949 & 0.0307 & 0.3255 & 0.5594 & 0.3678 & 0.3663 & 0.6530 \\
$J=6$ & 0.4214 & 0.2948 & 0.0307 & 0.3255 & 0.5595 & 0.3678 & 0.3663 & 0.6530 \\
$J=8$ & 0.4214 & 0.2948 & 0.0307 & 0.3255 & 0.5595 & 0.3678 & 0.3663 & 0.6530 \\
\hline
\end{tabular}

Note: $P$ is price of materials, $C$ is consumption, $I$ is investment, $Y$ is output, $S$ is inventory stock, $X$ is total ordering of materials, $M$ is materials used in production, and $W$ is real wage. 
Table A2. The Steady-State Distribution of Inventory Firms

\begin{tabular}{lccccccc}
\hline \hline Vintage $(j)$ & Active firms & 1 & 2 & 3 & 4 & 5 & 6 \\
\cline { 2 - 8 } Distribution $\omega\left(s_{j}\right)$ & & 0.259 & 0.251 & 0.220 & 0.160 & 0.082 & 0.028 \\
Inventories $s_{j}$ & 1.652 & 1.129 & 0.693 & 0.346 & 0.105 & 0.006 & 0.000 \\
\hline
\end{tabular}

Note: As our model contains a long-run trend which is absent in KT's model, the numbers in the table are slightly different from KT's (2007a) results because of the different calibrations. 
Table A3. Steady-State Distribution of Final-Goods Firms

\begin{tabular}{lcccccccc}
\hline \hline Vintage $(j)$ & & Active firms & 1 & 2 & 3 & 4 & 5 & 6 \\
Distribution $\omega\left(s_{j}\right)$ & Our Method & & $\mathbf{0 . 2 6 6}$ & $\mathbf{0 . 2 5 7}$ & $\mathbf{0 . 2 2 4}$ & $\mathbf{0 . 1 6 0}$ & $\mathbf{0 . 0 7 6}$ & $\mathbf{0 . 0 1 7}$ \\
& KT & & 0.268 & 0.258 & 0.224 & 0.159 & 0.074 & 0.017 \\
& & & & & & & & \\
Inventory Stocks $s_{j}$ & Our Method & $\mathbf{1 . 7 0 2}$ & $\mathbf{1 . 1 6 3}$ & $\mathbf{0 . 7 1 2}$ & $\mathbf{0 . 3 4 9}$ & $\mathbf{0 . 0 9 8}$ & $\mathbf{0 . 0 0 2}$ & $\mathbf{0 . 0 0 0}$ \\
& KT & 1.694 & 1.155 & 0.705 & 0.343 & 0.094 & 0.003 & 0.000 \\
& & & & & & & & \\
Fraction adjusting $F\left(\varepsilon_{j}^{*}\right)$ & Our Method & & $\mathbf{0 . 0 3 4}$ & $\mathbf{0 . 1 2 9}$ & $\mathbf{0 . 2 8 7}$ & $\mathbf{0 . 5 2 6}$ & $\mathbf{0 . 8 0 7}$ & $\mathbf{0 . 8 3 5}$ \\
& KT & & 0.036 & 0.132 & 0.292 & 0.534 & 0.806 & 0.838 \\
\hline
\end{tabular}

Note: Numbers in bold font are obtained by applying our solution method to KT's benchmark model. The numbers corresponding to KT are directly taken from Table 2 in Khan and Thomas (2007a). 
Table A4. Business Cycle Moments

\begin{tabular}{lcccccc}
\hline \hline $\begin{array}{l}\text { A. Volatility relative to GDP } \\
\quad \text { Our method }\end{array}$ & 0.846 & 0.364 & 6.101 & 0.695 & 1.688 & 1.374 \\
$\quad$ KT & 0.839 & 0.345 & 6.318 & 0.722 & 1.677 & 1.347 \\
B. Correlation with GDP & & & & & & \\
$\quad \begin{array}{l}\text { Our method } \\
\text { KT }\end{array}$ & 0.995 & 0.888 & 0.988 & 0.973 & 0.999 & 0.987 \\
& 0.994 & 0.864 & 0.982 & 0.973 & 0.999 & 0.985 \\
\hline
\end{tabular}

Note: FS: final sale; C: consumption; I: investment; H: hours worked; X: order of intermediate goods; M: intermediate goods input. All reported moments are simulated moments under the HP filter. KT's results are directly taken from Table 5 in Khan and Thomas (2007a). 

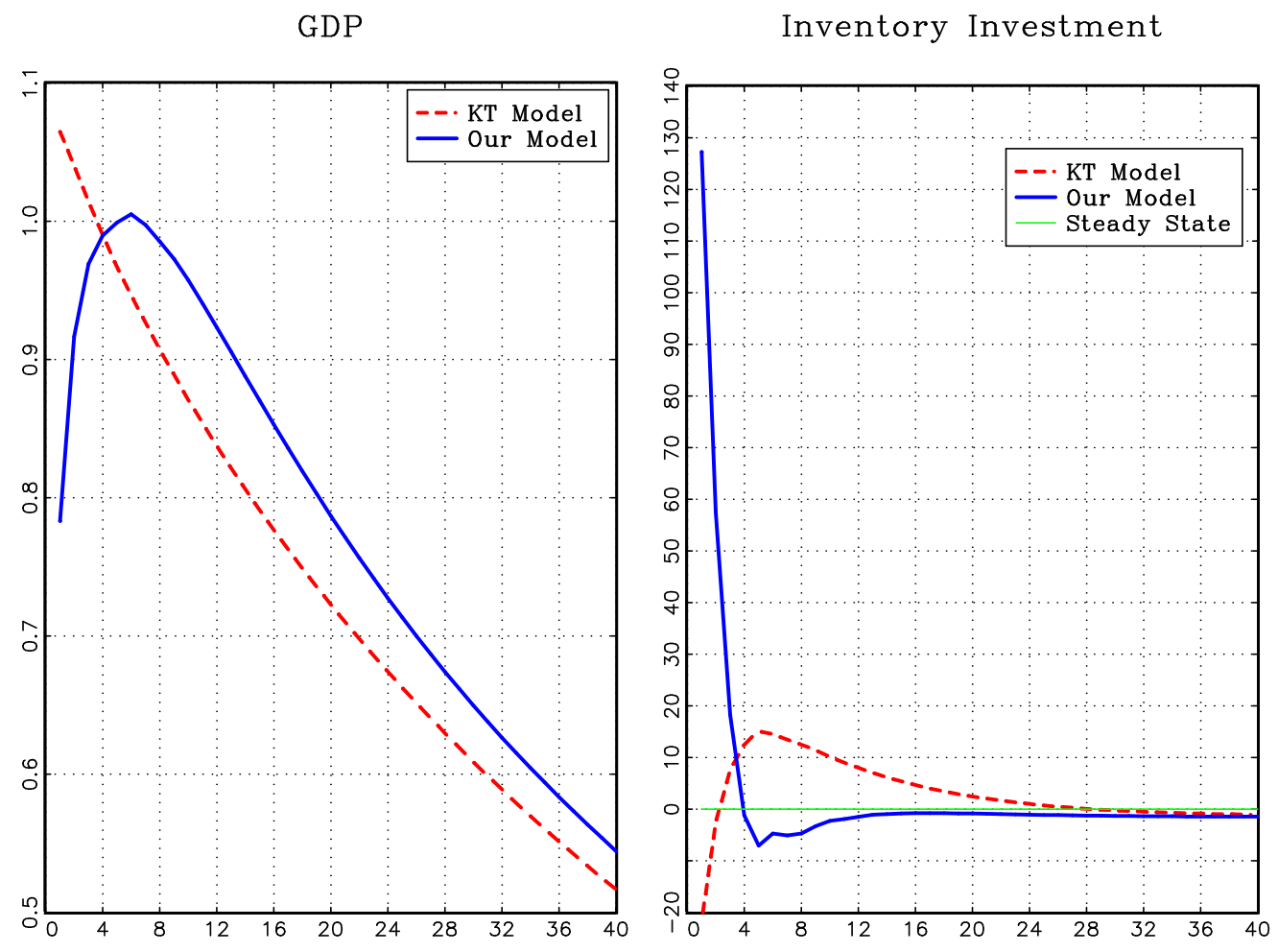

Figure 1. Impulse Responses to a Demand Shock. 